OPEN ACCESS

Edited by: Pavel Sumazin Baylor College of Medicine, United States

Reviewed by: Christian Bär

Hannover Medical School, Germany Eleonora Leucci, KU Leuven, Belgium

${ }^{*}$ Correspondence: Mariangela Morlando mariangela.morlando@unipg.it

Specialty section:

This article was submitted to Stem Cell Research,

a section of the journal Frontiers in Cell and Developmental Biology

Received: 15 January 2020 Accepted: 31 March 2020

Published: 06 May 2020

Citation:

Salvatori B, Biscarini S and Morlando M (2020) Non-coding RNAs in Nervous System Development and Disease.

Front. Cell Dev. Biol. 8:273 doi: 10.3389/fcell.2020.00273

\section{Non-coding RNAs in Nervous System Development and Disease}

\author{
Beatrice Salvatori ${ }^{1}$, Silvia Biscarini' ${ }^{1}$ and Mariangela Morlando ${ }^{2 *}$ \\ 1 Center for Life Nano Science@Sapienza, Istituto Italiano di Tecnologia, Rome, Italy, ${ }^{2}$ Department of Pharmaceutical \\ Sciences, "Department of Excellence 2018-2022", University of Perugia, Perugia, Italy
}

The rapid advance of RNA sequencing technologies contributed to a deep understanding of transcriptome composition and has allowed the discovery of a large number of non-coding RNAs (ncRNAs). The ability of these RNA molecules to be engaged in intricate and dynamic interactions with proteins and nucleic acids led to a great expansion of gene expression regulation mechanisms. By this matter, ncRNAs contribute to the increase in regulatory complexity that becomes highly specific between tissues and cell types. Among the ncRNAs, long non-coding RNAs (IncRNAs) and circular RNAs (circRNAs) are especially abundant in nervous system and have been shown to be implicated in its development, plasticity and aging as well as in neurological disorders. This review provides an overview of how these two diverse classes of ncRNAs control cellular processes during nervous system development, physiology, and disease conditions with particular emphasis on neurodegenerative disorders. The use of ncRNAs as biomarkers, tools, or targets for therapeutic intervention in neurodegeneration are also discussed.

Keywords: ncRNAs, circRNAs, neurodegenerative diseases, biomarkers, therapeutics, neuronal development, synaptic activity

\section{INTRODUCTION}

The development and function of the nervous system relies on complex and well-orchestrated gene expression regulation occurring at multiple levels, from transcription to RNA processing, translation, and decay. New discoveries in transcriptomics, facilitated by technical advances in next generation sequencing and computational biology, have revealed the existence of a plethora of transcripts lacking coding potential but exerting an intense regulatory activity in a wide range of biological processes including neuronal development, differentiation, and function. These transcripts belong to the heterogeneous family of non-coding RNAs (ncRNAs) composed by several classes of genes, producing smaller molecules such as microRNAs (miRNAs), and longer transcripts that can be processed to form long non-coding RNAs (lncRNAs) and circular RNAs (circRNAs). Studies in the field of lncRNA and circRNA molecules have accelerated considerably during the last few years and major interest has grown in the use of these molecules as diagnostic and therapeutic targets in neurodegenerative diseases (Derrien et al., 2012; Salta and De Strooper, 2017). 
LncRNAs are defined as a heterogeneous class of molecules longer than 200 nucleotides (nts) with no protein coding capacity. Their biogenesis is similar to that of mRNAs with RNA Polymerase II (RNAPII) engaging in their transcription. Nascent non-coding transcripts are often subjected to capping, canonical and alternative splicing as well as polyadenylation (Quinn and Chang, 2016). LncRNAs show tissue-specific expression, are generally present at low levels compared to the coding counterparts and show relatively low evolutionary conservation (Cabili et al., 2011; Derrien et al., 2012). Despite few examples, they generally lack an open reading frame (ORF) and influence gene expression at different levels through a variety of mechanisms of action, including recruitment of chromatin modifiers and transcription factors, regulation of three-dimensional chromatin folding, control of mRNA processing, translation and decay (Rinn and Chang, 2012; Fatica and Bozzoni, 2014).

In addition to these linear ncRNAs with distinct $5^{\prime}$ and $3^{\prime}$ ends, a group of circRNAs with covalently closed ends has recently gained attention. Initially discovered as plant viroids and hepatitis delta virus (Sanger et al., 1976; Kos et al., 1986) only in recent years the high-throughput RNA sequencing coupled with circRNA-specific bioinformatic algorithms revealed that 1000s of circRNA molecules are produced from a large fraction of genes in metazoans (human, mouse, zebrafish, worm, fruit fly) (Salzman et al., 2012; Jeck et al., 2013; Jeck and Sharpless, 2014; Salzman, 2014; Wang et al., 2014). Their biogenesis relies on a peculiar splicing reaction called back-splicing that joins a downstream $5^{\prime}$ splice site to an upstream $3^{\prime}$ splice site. Not much is known about their function, however, the few examples that have been characterized have revealed that circRNAs can potentially regulate gene expression both at transcriptional and post-transcriptional level (Kristensen et al., 2019).

Notably both lncRNAs and circRNAs are preferentially expressed in the nervous system and resulted to be dynamically regulated during neuronal development as well as in response to neuronal activity (Kim et al., 2010; Mercer et al., 2010; Derrien et al., 2012; Lipovich et al., 2012; Aprea et al., 2013; Rybak-Wolf et al., 2015; You et al., 2015; Biscarini et al., 2018). They also show highly restricted expression in various anatomic brain regions and cell structures (Mercer et al., 2008; Rybak-Wolf et al., 2015; You et al., 2015). These dynamics and region-specific expression patterns strongly suggest that lncRNAs and circRNAs may play key roles in nervous system development and function. Moreover, recent studies have also shown that, similar to protein coding genes, dysregulation of ncRNA molecules can affect proper nervous system development and function thus contributing to the onset and progression of neurological diseases (Shao and Chen, 2016; Wang et al., 2018a).

This review provides a comprehensive description of lncRNA and circRNA biogenesis and function highlighting their involvement in nervous system development and physiology. It also underlines the implication of ncRNA deregulation in diverse neurodegenerative disorders and ultimately how ncRNAs might serve as suitable diagnostic biomarkers and therapeutic targets.

\section{LONG NON-CODING RNAS: IDENTIFICATION AND GENOMIC CHARACTERIZATION}

Analysis of transcriptomes through a high-resolution RNA sequencing (RNA-seq) is one of the most robust methodologies for the de novo identification of IncRNAs (Mortazavi et al., 2008).

Large scale studies from multiple sources of data such as DNAse hypersensitivity and chromatin state maps released from the ENCODE (Encyclopedia of DNA Elements) consortium, revealed that $93 \%$ of the human genome is actively transcribed and $39 \%$ consists of transcriptional units composed by promoter and poly $(\mathrm{A})$ signals: strikingly only a little more than $1 \%$ is protein coding. Analysis on multiple human cell and tissue types confirmed that lncRNAs largely outnumber the coding elements, are highly expressed in the nervous system and although their gene body is poorly conserved, the promoter regions and their structural motifs show higher evolutionary constraints (Mercer et al., 2008; Guttman et al., 2009; Derrien et al., 2012, 2014; Hon et al., 2017). Ambitious projects for the functional annotation of the mammalian genome (FANTOM) confirmed that lncRNAs are pervasively transcribed, producing a comprehensive understanding on the genomic organization of more than 50,000 lncRNA loci. Capped Analysis of Gene Expression (CAGE) linked with computational analyses shows that lncRNAs have a heterogeneous genomic organization and can be found: (i) as independent transcriptional units (intergenic RNAs or lincRNAs); (ii) transcribed divergent from coding genes thus sharing the same promoter (divergent lncRNAs); (iii) transcribed from intronic regions (intronic lncRNAs) or enhancer regions (eRNAs); (iv) transcribed as antisense RNAs with respect to coding genes (natural antisense transcripts, NATs) (Figure 1). Notably, around $70 \%$ of the mammalian coding genes show evidence of antisense transcription, producing ncRNAs that partially or completely overlap with their sense coding strand, their promoter or their regulatory regions (Zhang et al., 2006; Wanowska et al., 2018). Upon evidence of such widespread presence, the importance of NATs and their regulatory relationship with their sense counterparts were deeply dissected for many disease-associated genes and were shown to be particularly relevant in neurodegeneration and for the repeat expansion phenomenon, as it will be described in the following paragraphs.

\section{CIRCRNAS: IDENTIFICATION AND BIOGENESIS}

The identification of circRNAs in mammals happened in a serendipitous manner when RNA-seq of libraries prepared from ribosome-depleted RNA were computed in order to map noncanonical RNAs derived from genome rearrangements. The work by Salzman et al. (2012) led to the identification of a class of transcripts derived from coding loci and made by exons joint in a reverse order with respect to the one encoded in the genome. These transcripts were demonstrated to be circular in 


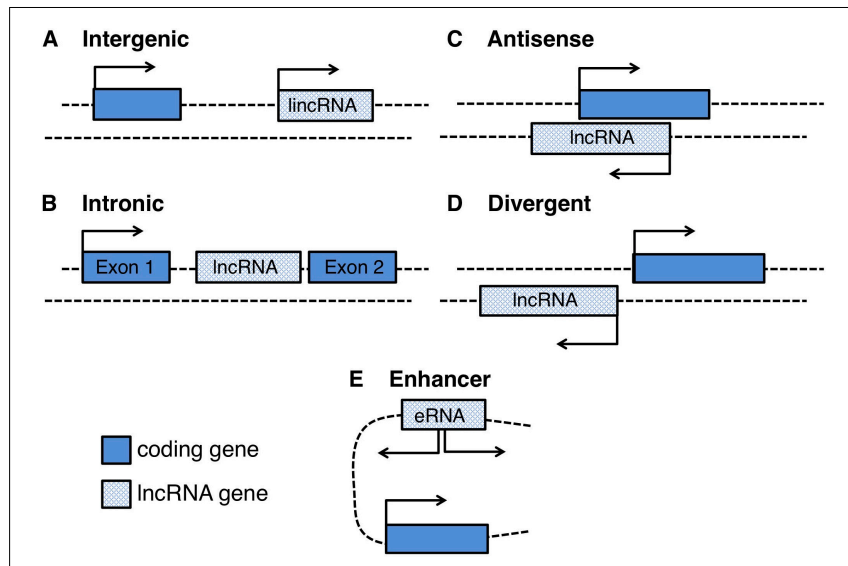

FIGURE 1 | Schematic representation of the genomic loci of different long non-coding RNAs: (A) intergenic RNAs (lincRNAs), located between two protein coding-genes, (B) intronic IncRNAs, located inside introns of protein coding-genes, (C) natural antisense IncRNAs (NATs), transcribed in an antisense orientation with respect to a protein coding-gene (D) divergent IncRNAs originated from bidirectional transcription of protein-coding genes, and $(\boldsymbol{E})$ enhancer RNAs (eRNAs) transcribed from bidirectional transcription of enhancer regions.

shape and to derive form a non-canonical splicing event named back-splicing (Salzman et al., 2012; Jeck et al., 2013); indeed, as a consequence of this event, circRNAs result to contain a downstream splice donor joint to an upstream splice acceptor (the back-splice junction, BSJ) (Figure 2A). Nowadays, the standard procedure adopted in order to identify circRNAs is the high depth RNA-seq of Ribosomal RNA depleted samples (Glazar et al., 2014). Eventually, the addition of an exonuclease treatment (for instance RNAse R) or poly(A) plus selection limits the presence of linear RNAs thus improving the sequence coverage of circRNAs (Jeck et al., 2013; Panda et al., 2017). Moreover, several pipelines have been developed so far in order to compute the RNA-seq datasets for identifying circRNAs, and is worth mentioning: find_circ (Memczak et al., 2013), CIRCexplorer (Zhang et al., 2014), circBase (Glazar et al., 2014), circRNA_finder (Westholm et al., 2014), and CIRI2 (Hansen, 2018). Since these algorithms differ significantly in the pool of circRNA species they predict, it is recommended to use at least two independent algorithms to ensure proper annotation of the BSJs (Szabo and Salzman, 2016).

Two elements have been described, so far, to facilitate backsplicing: intronic cis-elements and/or protein factors acting in trans (Figures 2B,C).

Analyses of the intronic sequences of genes producing circRNAs revealed that introns flanking circularizing exons are longer than the average and often contain complementary inverted repeats (Jeck and Sharpless, 2014; Liang and Wilusz, 2014; Westholm et al., 2014; Zhang et al., 2014). In humans the repetitive elements are frequently represented by ALU sequences (Jeck et al., 2013; Ivanov et al., 2015) and recent studies showed that the circularization of such exons is affected by the activity of the exonucleases DHX9 and of the editing enzyme ADAR (Rybak-Wolf et al., 2015; Aktaş et al., 2017) both interfering with intron pairing (Figure 2D). Notably, a global decrease in ADAR mediating editing of ALU sequences has been observed during the differentiation of human embryonic stem cells toward the neuronal fate (Osenberg et al., 2010); this might explain the overall upregulation of circRNA production occurring during neuronal differentiation observed in both flies and mammals (Rybak-Wolf et al., 2015).

Nevertheless, the presence of intronic repeats per se is not sufficient to explain the dynamic and tissue specific expression of circRNAs, that instead relies on the activity of RNA binding proteins (RBPs). In most of the cases, RBPs bind introns in a sequence specific manner and, through dimerization, promote the back-splicing reaction (Figure 2C). Muscle blind (MBL) in Drosophila, Quaking (QKI) and Fused in Sarcoma (FUS) in mammals as well as multiple hnRNPs (heterogeneous nuclear ribonucleoproteins) and SR (serine-arginine) proteins are directly involved in facilitating circRNA biogenesis (AshwalFluss et al., 2014; Conn et al., 2015; Kramer et al., 2015; Errichelli et al., 2017; Fei et al., 2017).

It has been also demonstrated that the back-splicing reaction can be further regulated by exon skipping events: the lariat containing the skipped exon can be re-spliced thereby producing a mature circRNA (Figure 2E) (Barrett et al., 2015). This mechanism allows the generation of both linear and circular RNAs from a single precursor transcript.

Finally, intron lariats that escape debranching can give rise to a different class of circRNAs, named ciRNAs (circular intronic circRNAs) (Figure 2A). Even though, the molecular mechanisms of ciRNA biogenesis is still unknown it has been shown that a consensus RNA motif near the $5^{\prime}$ splice site confers intron lariats the resistance to the debranching activity (Zhang et al., 2013).

\section{LONG NON-CODING RNA FUNCTIONS}

At the beginning of the post-genomic era scientists realized that the genome is pervasively transcribed (Lander et al., 2001). By that time, the pioneering studies on H19 and Xist were the only few examples showing the functional role of IncRNAs on imprinting (Bartolomei et al., 1991; Brown et al., 1991). However, the remainder of the full plethora of ncRNAs, their transcriptional significance and functional role, remained controversial for a long time. It was only after RNAseq techniques were fully available that we could appreciate innovative studies that explored and characterized lncRNA molecular functions in different cellular and molecular contexts. For instance, the studies on MEG3, MALAT1, HOTAIR, and lincMD1 have revealed the critical and versatile role of IncRNAs in shaping the complex mammalian regulatory networks, through different mechanisms of action (Rinn et al., 2007; Tripathi et al., 2010; Cesana et al., 2011).

Structural features in the lncRNA sequence play a key role in the assembly and regulation of multi-molecular complexes, by controlling the affinity for DNA, RNA, and proteins (Wang and Chang, 2011; Fatica and Bozzoni, 2014). It has been shown that, due to the lack of a functional ORF, the poor conservation of lncRNA molecules only reflects the lower sequence constraint 


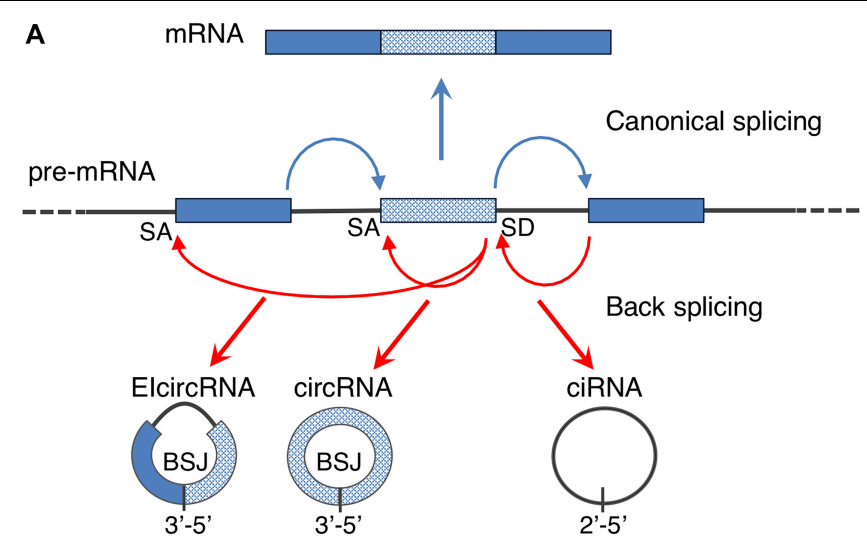

B
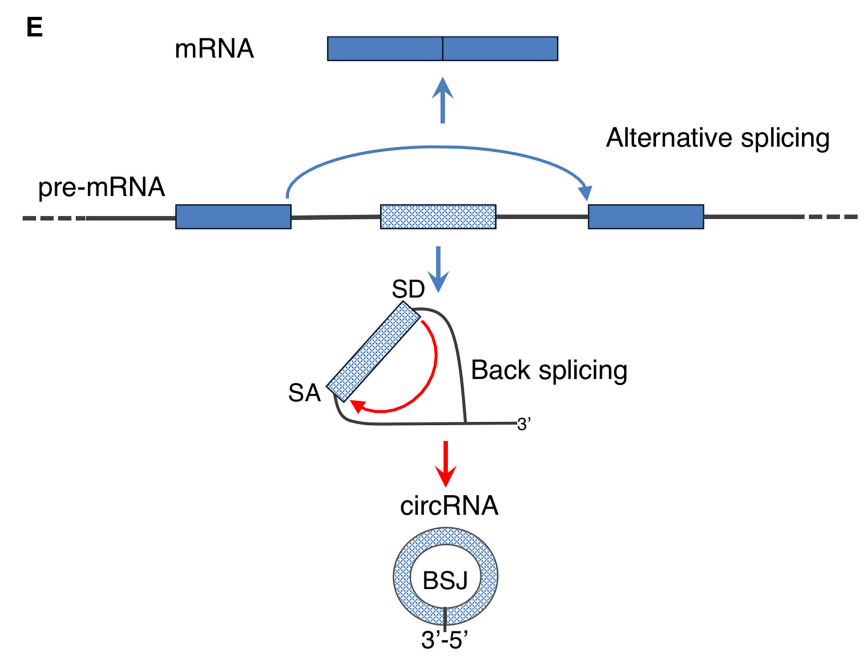

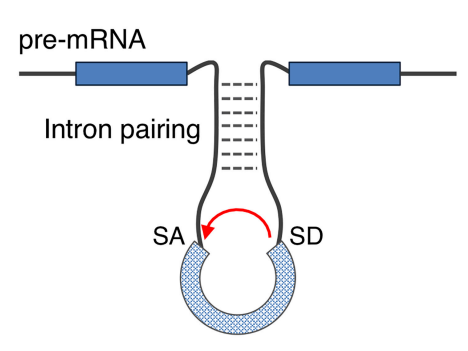

C

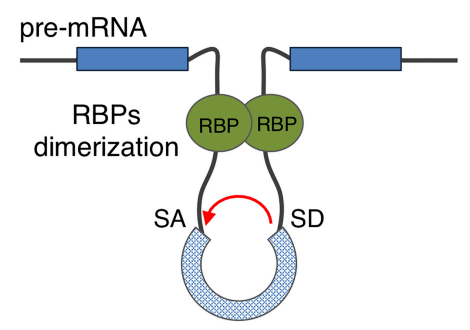

D

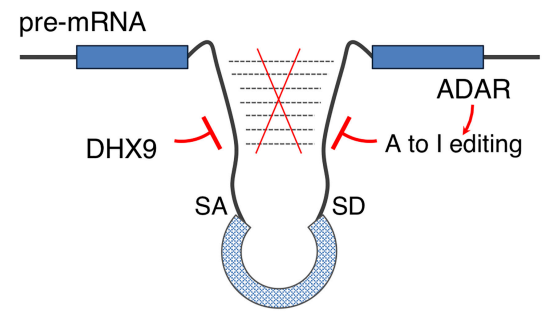

FIGURE 2 | Regulation of circular RNA biogenesis: (A) canonical splicing generates mature mRNA while back-splicing can give rise to different kinds of circular transcripts: circRNAs can derive from exonic regions (circRNA), from introns (ciRNA) or from both exons and introns (ElcircRNA). (B,C) Back-splicing mechanism can be driven by intron pairing or RNA binding proteins (RBPs) dimerization. (D) Inhibitory activity of ADAR and DHX9 enzymes on back-splicing driven by intron pairing. (E) As a consequence of alternative splicing events, lariat containing the skipped exon can be re-spliced producing a mature circRNA. Through this mechanism both mature mRNA and a circRNA can be produced from a single pre-mRNA.

and that, instead, conservation of their secondary structures is important for maintaining the functionality of these molecules (Smith et al., 2013; Derrien et al., 2014). On the other hand, lncRNAs show high sequence conservation in their promoter region where binding sites for important regulatory transcription factors allow their tissue-specific expression patterns (Guttman et al., 2009). Indeed, in human and murine embryonic stem cells $60 \%$ of lncRNAs identified are divergently transcribed with respect to coding genes and share the same promoter, leading to a coordinated expression of coding and non-coding transcripts during development and differentiation (Sigova et al., 2013).

LncRNAs can be localized in the nucleus, in the cytoplasm and even in or with the mitochondria, and their localization may anticipate their mode of action (Rackham et al., 2011; Cabili et al., 2015; Leucci et al., 2016).

Inside the nucleus the scaffolding property of lncRNAs allows to guide protein factors or complexes to specific genomic loci, thus regulating their transcription and maturation in a positive or negative manner (Engreitz et al., 2016; Morlando and Fatica,
2018) (Figures 3A-C). Among these lncRNAs are Xist (recruits PRC2 for H3K27me3 and RYBP-PRC1 for H2A ubiquitylation; Zhao et al., 2010; Tavares et al., 2012), HOTTIP (recruits WDR5/MLL complex for histone $\mathrm{H} 3$ lysine 4 trimethylation; Wang et al., 2011) and eRNAs (recruit transcription factors and RNAPII; Kim et al., 2010; Lai et al., 2013). Cytoplasmic lncRNAs regulate gene expression at post-transcriptional level recruiting the appropriate protein machineries affecting the stability (lncRNA TINCR; Kretz et al., 2013), decay (1/2-sbsRNAs lncRNA; Gong and Maquat, 2011), translational activation (lnc31; Dimartino et al., 2018) and repression (linc-p21; Yoon et al., 2012) of mRNAs (Figure 3D). Notably, many evidence reports that NATs have an impact on the sense coding strand in the cytoplasm by using their sequence complementary in order to mask miRNA binding sites (BACE1-AS; Faghihi et al., 2008) or to influence translation (Uchl1-AS; Carrieri et al., 2012). LncRNAs can also act as decoy molecules, which may inactivate transcription factors in the nucleus or sequester miRNAs and RBPs in the cytoplasm thus preventing them to bind their natural 


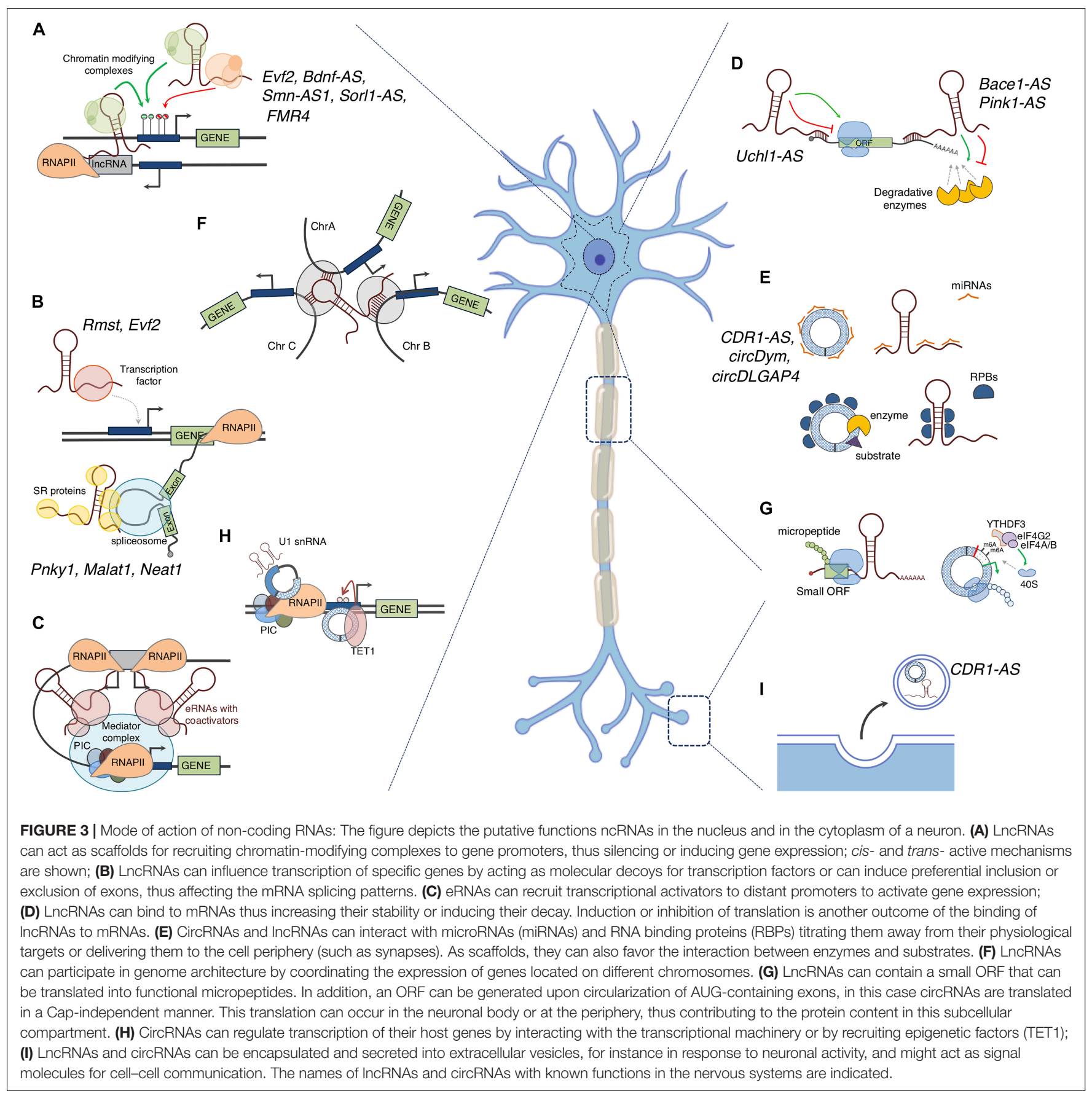

targets (Jpx lncrna, Sun et al., 2013; linc-ROR, Wang et al., 2013; linc-MD1, Cesana et al., 2011; lncMyoD, Gong et al., 2015) (Figures 3B,E).

Moreover, mRNA processing can be modulated by lncRNAs (Romero-Barrios et al., 2018). NEAT1 and MALAT1 are two examples of lncRNAs able to regulate the splicing of specific pre-mRNAs by modulating the phosphorylation state of splicing factors (Tripathi et al., 2010; Cooper et al., 2014) (Figure 3B).

For nuclear lncRNAs, cis- and trans- regulatory mechanisms have been described. Cis-acting lncRNAs affect the expression of proximal loci; examples are the NATs that interfere with the expression of the antisense coding gene by repressing or promoting its expression. The cis-regulatory mechanism is mediated via NAT transcription per se or through RNARNA interactions with the overlapping transcript. In this latter case, splice sites can be masked leading to alternative splicing events or transcript availability can be reduced through nuclear retention (Wanowska et al., 2018). A very common mechanism of cis-activity of NATs is the recruitment of epigenetic machineries, like the PRC2 thus influencing the chromatin state of their 
antisense coding gene ( $\mathrm{Yu}$ et al., 2008; Modarresi et al., 2012) (Figure 3A).

Differently, trans-active lncRNAs affect the expression of target genes that are located in different chromosomes (Chu et al., 2011; Vance et al., 2014) (Figure 3A).

In the last few years several evidence has emerged tightly linking transcription and the three-dimensional organization of the genome, so adding an additional layer of complexity in gene expression regulation (Mele and Rinn, 2016). However, the cause-consequence relationship between transcription and genome re-organization was not univocally determined (Osborne et al., 2004; Zink et al., 2004). Many lncRNAs might participate in genome architecture through the simple act of transcription, independently of the mature RNA product or of their generally low abundance and lack of sequence conservation (Hangauer et al., 2013; Ballarino et al., 2018). Moreover, some mature lncRNA transcripts, such as XIST, FIRRE, and NEAT1, are known to play a role in organizing nuclear architecture (Mao et al., 2011; Engreitz et al., 2013; Hacisuleyman et al., 2014) (Figure 3F).

Ultimately, many apparent non-coding transcripts were revelaled to be associated to the ribosome and to produce small peptides (Hube and Francastel, 2018) (Figure 3G). The noncoding definition of lncRNAs relies on the arbitrary threshold of an ORF shorter than 100 aminoacids (Carninci et al., 2005); however, ribosome profiling revealed that translation is more pervasive than previously thought (Ingolia, 2014). Examples of lncRNA-derived micropeptides are myoregulin (encoded by the LINC00948 RNA in humans and by the 2310015B20Rik RNA in mice) and DWORF (encoded by LOC100507537 gene in humans and by NONMMUG026737 gene in mice) which regulate muscle performance by affecting the activity of the key calcium pump SERCA in a negative and positive manner respectively (Anderson et al., 2015; Nelson et al., 2016). Notably, DWORF may be useful therapeutic molecule in improving the cardiac muscle function of mammals with heart disease (Nelson et al., 2016). Ribosome associated lncRNAs have also displayed a dual function both as peptide coding and as ncRNA and are now termed bifunctional (Li et al., 2017). The lncRNA Oskar, involved in oocyte development is a prototypical example in this expanding research area (Jenny et al., 2006).

\section{CIRCULAR RNA FUNCTIONS}

The majority of circRNAs identified shows cytoplasmic localization even though there are some examples of nuclear localized molecules (Salzman et al., 2012; Jeck et al., 2013; Li et al., 2015a; Errichelli et al., 2017; Chen et al., 2018a). In these two compartments circRNAs control gene expression at different levels through mechanisms that have not been fully characterized.

Indeed, the function of few circRNAs has been unveiled so far. Several studies reported circRNAs exerting miRNA "sponge" activity, thereby altering the expression of the miRNA targets (Hansen et al., 2013; Memczak et al., 2013; Zheng et al., 2016;
Bach et al., 2019) (Figure 3E). The most notable cases are the mouse Sry and the human CDR1-AS (also known as ciRS-7) which respectively, possess 16 binding sites for miR-138 and more than 70 evolutionary conserved binding sites for miR-7 (Hansen et al., 2013; Memczak et al., 2013). In particular CDR1AS is expressed much more than any other housekeeping gene in mouse and human brain and this, together with the high number of miR-7 binding sites, makes the competing activity of CDR1AS stoichiometrically relevant in neuronal tissue (Hansen et al., 2013). More recently, Piwecka et al. (2017) showed that CDR1AS may modulate the activity of miR-7 by acting on its stability. Consistently with these data, the depletion of CDR1-AS causes the modulation of miR-7 targets mRNAs both in vivo and in vitro (Hansen et al., 2013; Memczak et al., 2013).

In addition to miRNAs, circRNAs can interact with RBPs. They may sequester them from other targets or regulate their stability/activity (Ashwal-Fluss et al., 2014; Du et al., 2017; Liu et al., 2019; Rossi et al., 2019); circRNAs may also act as molecular scaffolds to allow enzymes and substrates to become adjacent (Du et al., 2017; Zeng et al., 2017) (Figure 3E).

Examples of circRNAs containing an ORF, thus serving as templates for translation, have also been described (Legnini et al., 2017; Pamudurti et al., 2017; Yang et al., 2018; Zhang et al., 2018a; Liang et al., 2019). Given their circular structure, the translation of these circRNAs relies on a Cap-independent mechanism and on the presence of the N6-methyl-adenosine modification. This latter promotes the binding of the reader protein YTHDF3 and the IRES-specialized translation initiation factor eIF4G2 (Legnini et al., 2017; Yang et al., 2017) (Figure 3G).

In the nucleus, circRNAs can participate in gene expression regulation at transcriptional level. For instance, circPAIP2 and FECR1 circRNA have been described to regulate the transcription of their parental genes through two diverse mechanisms: interacting with transcription machinery, whilst the latter by recruiting the TET1 DNA demethylase (Li et al., 2015a; Chen et al., 2018a) (Figure 3H).

\section{ROLE OF NON-CODING RNAS IN THE PHYSIOLOGY AND DEVELOPMENT OF THE NERVOUS SYSTEM}

LncRNAs show a crucial role in many stages of neuronal differentiation and specification by participating in gene expression control at the epigenetic, transcriptional, and posttranscriptional levels. LncRNA molecules may regulate the exit from the pluripotency state, influence cell fate choice during neural development and contribute to the synaptic activity in mature cells (Zalfa et al., 2003; Zhong et al., 2009; Guttman et al., 2011; Ng et al., 2012; Vance et al., 2014). The IncRNA mechanism of action is strictly linked to their secondary structure and their scaffolding activity, which translates into the ability to regulate gene expression by binding and recruiting secondary factors onto regulative domains. Here we report some examples that are noteworthy for the study of nervous system differentiation and in the maintenance of its physiological functionality (Table 1). RMST is a lncRNA controlled by the master regulator REST 
during neural differentiation (Ng et al., 2013). Depletion of RMST prevents cells from exiting the embryonic stem cell state and inhibits the initiation of neural differentiation. Indeed, RMST acts as a scaffold RNA by guiding the transcription factor Sox 2 to the promoter of key neurogenesis-promoting genes, such as DLX1, ASCL1, HEY2, and SPS (Ng et al., 2013).

Evf2 lncRNA also regulates cell-fate choice and is a clear example of how RNA secondary structure may contribute through a variety of modes of action. This lncRNA is a NAT to the DLX6 gene and recruits the DLX transcription factor and the methyl-CpG-binding protein (MECP2) to the promoters of interneuron lineage genes (DLX5, DLX6, and GAD1) through both cis- and trans- acting scaffolding mechanisms, ultimately controlling the excitatory-inhibitory neurons balance in vivo (Bond et al., 2009). In addition, the Evf2 transcript is implicated in controlling the methylation state of DLX5/6e enhancer through a chromosomal looping mechanism, thus regulating the expression of DLX5/6 locus (Berghoff et al., 2013). However, how the Evf2 methylation control is combined with the recruitment of DLX and MECP2 is still unknown.

Pnky is a lncRNA that is few kilobases divergent from the Pou3f2 gene. This lncRNA, whose expression peaks in dividing neural stem cells (NSCs) and decreases during neuronal differentiation, is essential for self-renewal of the NSC population. Pnky interacts with the splicing regulator PTBP1 and controls the expression and alternative splicing of a core set of targets involved in neurogenesis (Ramos et al., 2015). Through this mechanism Pnky regulates the balance between self-renewal and differentiation of NSCs.

An interesting variation of this mode of action has been described for the lncRNA Cyrano that is highly expressed in the nervous system and recently shown to be implicated in a whole non-coding regulatory circuitry (Kleaveland et al., 2018). Kleaveland et al. (2018) identified a post-transcriptional regulatory network in which Cyrano binds miR-7, leading to its degradation through a target RNA-directed miRNA degradation mechanism (TDMD). Mir-7 degradation in nervous tissue blocks the repression of its RNA targets among which the circRNA CDR1-AS. Notably, Cyrano knock-down in zebrafish causes a neurodevelopmental phenotype (Ulitsky et al., 2011).

LncRNAs specifically expressed in in vitro derived murine motor neurons have also been identified (Biscarini et al., 2018). Two interesting cases are Lhxlos and IncMN-1 that are divergent from Lhx1 and Pcdh10 protein-coding genes respectively. Lhx1 encodes for a morphogenetic factor of the LIM family involved in lateral motor neuron differentiation, head development and motor neuron axon guidance, while Pcdh10 codes for a protocadherin involved in motor neuronal cell adhesion (Tsuchida et al., 1994; Hunter and Rhodes, 2005; Machado et al., 2014). Notably, Lhxlos and lncMN-1 show strong co-regulation with two divergent coding transcripts in both mouse and human motor neurons.

LncRNAs were shown to participate in mature neuron plasticity and physiology. Indeed, despite being post-mitotic cells, neurons need to maintain a high level of plasticity in order to be able to respond to stimuli and to re-arrange their synaptic network for accompanying processes such as learning, memory, cognition and recovery from injury or insult (CostaMattioli et al., 2009; West and Greenberg, 2011). The lncRNA $\mathrm{BC} 1 / \mathrm{BC} 200$ regulates synaptogenesis. This transcript is expressed in the developing and adult nervous system where is transported to dendrites (Muslimov et al., 1997). In these cellular structures BC1/BC200 interacts with FMRP and the translational machinery in order to control the formation of the $48 \mathrm{~S}$ complex leading to a repression of local translation at synapses (Wang et al., 2002; Zalfa et al., 2003). Moreover, the expression of $\mathrm{BC} 1 / 200$ is dynamically upregulated at specific synapses in response to neuronal activity, thus shaping the synaptic protein content (Muslimov et al., 1998).

MALAT1, initially characterized for its role in cancer metastasis, was then identified to have a role in synapse formation (Ji et al., 2003). This lncRNA is highly expressed in neurons and it is localized in nuclear speckles; MALAT1 controls the processing of synaptogenesis-related genes through the recruitment of SR-protein family members to transcription sites (Bernard et al., 2010).

Finally, some interesting mechanisms involving NATs have been shown to contribute to the regulation of neuronal plasticity. BDNF-AS, whose expression is dependent on neural activity also contributes to the decision between synaptic maintenance or elimination in response to the levels of stimulation by controlling the expression of its sense overlapping gene BDNF (Lipovich et al., 2012; Modarresi et al., 2012).

Similarly to lncRNAs, circRNAs have been recognized to play important roles in development and function of neuronal tissue (van Rossum et al., 2016) (Table 1). Recent studies have demonstrated that circRNAs are specifically enriched in brain tissue and in particular, they revealed that compared to other tissues, the mammalian brain contains the highest percentage of genes hosting circRNAs and that these genes hold the ability to produce the greatest number of distinct circRNAs (Rybak-Wolf et al., 2015).

Notably, neuronal circRNAs resulted to be regulated during embryonic development and conserved between rodents, pigs and humans (Westholm et al., 2014; Rybak-Wolf et al., 2015; Venø et al., 2015; Chen et al., 2018b). In a model system of neuronal differentiation the overall expression of circRNAs resulted to be significantly upregulated and gene ontologies of their host genes showed their enrichment in neuronal specific pathways such as neuron development, differentiation, and synaptic transmission (You et al., 2015). Other studies further showed that circRNAs result differentially expressed in various anatomic brain regions and at specific embryonic or postnatal stages (Rybak-Wolf et al., 2015; Venø et al., 2015). Moreover, based on differential expression between adult and aged brains, these studies also showed that the expression of specific circRNAs is aging-related (Westholm et al., 2014; Gruner et al., 2016; $\mathrm{Xu}$ et al., 2018). Some examples are the murine circRims 2 and circDym which are expressed more than $50 \%$ in adult cerebellum and circPldxnd 1 which instead is predominantly expressed in prefrontal cortex $(>60 \%)$ with respect to the other brain regions (Rybak-Wolf et al., 2015). In addition, Venø et al. (2015) found that during the porcine embryonic brain development the expression of clusters of specific circRNAs coincides with distinct 
TABLE 1 | List of ncRNAs with a known or potential function (asterisk) in neuronal physiology and disease.

\begin{tabular}{|c|c|c|c|c|c|c|}
\hline Name & Classification & $\begin{array}{l}\text { Proximal/overlapping } \\
\text { coding gene }\end{array}$ & Molecular function & Biological function & Disease & References \\
\hline RMST & lincRNA & $\mathrm{N} / \mathrm{A}$ & Decoy for transcription factor & $\begin{array}{l}\text { ESC self-renewal and } \\
\text { inhibition of neural } \\
\text { differentiation }\end{array}$ & N/A & Ng et al., 2013 \\
\hline Evf2 & NAT & Dlx6 & $\begin{array}{l}\text { Scaffold RNA for transcription } \\
\text { factors and chromatin } \\
\text { remodeling }\end{array}$ & $\begin{array}{l}\text { Neuronal differentiation } \\
\text { and development }\end{array}$ & $\mathrm{N} / \mathrm{A}$ & Bond et al., 2009 \\
\hline Pnky & Divergent & Pou3f2 & Decoy for splicing factors & $\begin{array}{l}\text { Neural Stem Cell } \\
\text { self-renewal }\end{array}$ & $\mathrm{N} / \mathrm{A}$ & Ramos et al., 2015 \\
\hline Cyrano & lincRNA & $\mathrm{N} / \mathrm{A}$ & $\begin{array}{l}\text { target RNA-directed miRNA } \\
\text { degradation }\end{array}$ & ESC self-renewal & N/A & Kleaveland et al., 2018 \\
\hline Lhx1os & Divergent & Lhx1 & Unknown & Neuronal Differentiation & ALS & Biscarini et al., 2018 \\
\hline LncMN-1 & Divergent & Pcdh10 & Unknown & Neuronal Differentiation & ALS & Biscarini et al., 2018 \\
\hline BC200 & Intronic & Epcam-DT & $\begin{array}{l}\text { Scaffold RNA for translation } \\
\text { factors }\end{array}$ & $\begin{array}{l}\text { Regulates translation at } \\
\text { synapsis }\end{array}$ & $A D$ & $\begin{array}{l}\text { Muslimov et al., 1998; } \\
\text { Wang et al., 2002; Zalfa } \\
\text { et al., } 2003\end{array}$ \\
\hline MALAT1 & lincRNA & $\mathrm{N} / \mathrm{A}$ & $\begin{array}{l}\text { Decoy for splicing factors, } \\
\text { paraspeckle }\end{array}$ & $\begin{array}{l}\text { Neuronal Stress } \\
\text { Response }\end{array}$ & $\begin{array}{l}\text { ALS, HD, FTD, } \\
\text { AD }\end{array}$ & $\begin{array}{l}\text { Ji et al., 2003; Bernard } \\
\text { et al., } 2010\end{array}$ \\
\hline BDNF-AS & NAT & Bdnf & Scaffold RNA & Synaptogenesis & $H D$ & $\begin{array}{l}\text { Lipovich et al., 2012; } \\
\text { Modarresi et al., } 2012\end{array}$ \\
\hline SMN-AS1 & NAT & Smn & Scaffold RNA & Neuronal Differentiation & SMA & d'Ydewalle et al., 2017 \\
\hline SORL1-AS & NAT & Sorl1 & Scaffold RNA & Unknown & $A D$ & Ciarlo et al., 2013 \\
\hline BACE1-AS & NAT & Bace1 & $\begin{array}{l}\text { RNA-RNA interaction for } \\
\text { miRNA masking }\end{array}$ & Beta amyloid formation & $A D$ & $\begin{array}{l}\text { Faghihi et al., 2008; } \\
\text { Faghihi et al., } 2010\end{array}$ \\
\hline UCHL1-AS & NAT & Uchl1 & $\begin{array}{l}\text { RNA-RNA interaction through } \\
\text { SINEUP }\end{array}$ & $\begin{array}{l}\text { Neuronal Stress } \\
\text { Response }\end{array}$ & $A D, P D$ & Carrieri et al., 2015 \\
\hline NEAT1 & lincRNA & $\mathrm{N} / \mathrm{A}$ & $\begin{array}{l}\text { Scaffold RNA for splicing } \\
\text { factors, Paraspeckle }\end{array}$ & $\begin{array}{l}\text { Neuronal Stress } \\
\text { Response }\end{array}$ & $\begin{array}{l}\text { ALS, HD, FTD, } \\
A D\end{array}$ & $\begin{array}{l}\text { Nishimoto et al., 2013; } \\
\text { An et al., } 2018\end{array}$ \\
\hline C9ORF72-AS & NAT & C9ORF72 & RNA foci & Unknown & ALS & $\begin{array}{l}\text { DeJesus-Hernandez } \\
\text { et al., 2011; } \\
\text { Cooper-Knock et al., } \\
\text { 2015b }\end{array}$ \\
\hline PINK1-AS & NAT & Pink1 & $\begin{array}{l}\text { RNA-RNA interaction in cis } \\
\text { on Pink1 }\end{array}$ & Mithocondrial function & PD & Scheele et al., 2007 \\
\hline FMR4 & NAT & Fmr1 & $\begin{array}{l}\text { Scaffold RNA in trans for } \\
\text { chromatin remodeling }\end{array}$ & $\begin{array}{l}\text { Neural precursor } \\
\text { proliferation }\end{array}$ & FXS, FXTAS & $\begin{array}{l}\text { Khalil et al., 2008; } \\
\text { Peschansky et al., } 2016\end{array}$ \\
\hline HTT-AS & NAT & $\mathrm{Htt}$ & $\begin{array}{l}\text { Decoy for transcription factor } \\
\text { in cis on } \mathrm{HTT}\end{array}$ & Unknown & $H D$ & Chung et al., 2011 \\
\hline ATXN8-OS & NAT & Sca8 & RNA foci & Unknown & SCA & Moseley et al., 2006 \\
\hline SCAANT1 & NAT & Sca7 & $\begin{array}{l}\text { Decoy for transcription factor } \\
\text { in cis on Sca7 }\end{array}$ & Unknown & SCA & Sopher et al., 2011 \\
\hline CDR1-AS & circRNA & CDR1 & miRNA sponge & Synaptic transmission & $A D, P D$ & $\begin{array}{l}\text { Hansen et al., 2013; } \\
\text { Memczak et al., 2013; } \\
\text { Piwecka et al., } 2017\end{array}$ \\
\hline circRims2 & circRNA & Rims2 & Unknown & Unknown & $\mathrm{N} / \mathrm{A}$ & Rybak-Wolf et al., 2015 \\
\hline circDym & circRNA & Dym & miRNA sponge & Microglial activation & $\begin{array}{l}\text { Depressive-like } \\
\text { behavior }\end{array}$ & $\begin{array}{l}\text { Rybak-Wolf et al., 2015; } \\
\text { Zhang et al., 2018b }\end{array}$ \\
\hline circPldxnd1 & circRNA & Pldxnd1 & Unknown & Unknown & N/A & Rybak-Wolf et al., 2015 \\
\hline circStau2 & circRNA & Stau2 & Unknown & Unknown & $\mathrm{N} / \mathrm{A}$ & Rybak-Wolf et al., 2015 \\
\hline circHomer1_a & circRNA & Homer1 & Unknown & $\begin{array}{l}\text { Homeostatic synaptic } \\
\text { plasticity* }^{*}\end{array}$ & $\mathrm{~N} / \mathrm{A}$ & You et al., 2015 \\
\hline mmu_circRNA_017963 & circRNA & Tbc1d30 & miRNA sponge ${ }^{\star}$ & $\begin{array}{l}\text { Apoptotic process, } \\
\text { transport and RNA } \\
\text { splicing, synaptic } \\
\text { functions* }\end{array}$ & $A D$ & Huang et al., 2018 \\
\hline circDLGAP4 & circRNA & Dlgap4 & miRNA sponge & $\begin{array}{l}\text { Cell viability, apoptosis, } \\
\text { mitochondrial damage, } \\
\text { and autophagy }\end{array}$ & $\mathrm{PD}$ & Feng et al., 2019 \\
\hline
\end{tabular}

N/A is for "Not Applicable." 
developmental transitions and that the maximum expression and complexity of circRNAs is reached at a time corresponding to the period of major neurogenesis (form day 48 to day 60). Finally, it has been also demonstrated that circRNA expression is modulated during in vitro differentiation of murine motor neurons with specific circRNAs exclusively expressed in this cell type (Errichelli et al., 2017).

All these data strongly support the idea that circRNAs play important biological functions during development and specification of the nervous system.

Besides the expression modulation, neuronal circRNAs also show an intriguing subcellular localization since they have been found to be enriched in synaptoneurosomes more than their linear counterparts (Rybak-Wolf et al., 2015; Venø et al., 2015; You et al., 2015). An example is circStau2 that is mainly located at synapses while the linear Stau2 is primarily cytoplasmic (RybakWolf et al., 2015). Furthermore, the most abundant neuronal circRNAs derive from genes encoding for proteins associated with synaptic functions (Venø et al., 2015; You et al., 2015). In this regard, You et al. (2015) demonstrated that circHomer1_a, which originates from the Homer1 gene encoding for a key protein in post-synaptic density regulation, reaches its highest expression and synaptic localization during synaptic plasticity in cultured hippocampal neurons (Meyer et al., 2014; You et al., 2015). In the same study, You et al. (2015) also analyzed the expression of circRNAs at various stages of brain development in mice (from E18 to P30) and showed that in hippocampal neurons an abrupt postnatal shift in circRNA expression (and not of the linear host transcripts) occurs when synaptogenesis begins. Lastly, mice carrying a deletion of the CDR1-AS genomic region exhibited defects in excitatory synaptic transmission and impaired sensorimotor gating; an increased spontaneous vesicle release was also observed in the neurons of these mice, suggesting that CRD1-AS might have a role in regulating synaptic transmission (Piwecka et al., 2017).

Even though, the molecular mechanism allowing the circRNAs delivery at the neuronal periphery is still unknown, all the findings suggest a role for these RNAs in the formation and activity of specific neuronal structures: circRNAs might be selectively transported to synapses to regulate their activity functioning as sponges/cargo for miRNAs and RBPs (Figure 3E). In this way they might indirectly regulate the expression of the miRNA/RBP-targeted mRNAs at synapses. Alternatively, synaptic circRNAs might function as signal molecules since they can also be packaged into vesicles and released into the synaptic cleft to influence neighboring cells (Li et al., 2015b; Lu and Xu, 2016) (Figure 3I).

\section{LONG NON-CODING RNAS IN NEURODEGENERATIVE DISEASES}

Alteration of lncRNA expression has been extensively described for many neuronal diseases together with their wide implication in the formation of aberrant molecular pathways (Salta and De Strooper, 2017). In addition, among the non-coding genes, lncRNAs are highly expressed in the nervous system and have been often observed to be located in proximity to neuronal genes and loci associated with neurodegenerative diseases (Qureshi et al., 2010; Wei et al., 2018). Starting from their genomic localization (intergenic, antisense, intronic, etc.) researchers focused on understanding the role that these molecules may play in cis or trans to control gene expression. As described above, several mechanisms of action have been observed and here we report some evidence where lncRNA activity is altered in neurodegenerative diseases (Table $\mathbf{1}$ ). Numerous examples are of NATs involved in neuronal processes and associated with neurodegeneration. NATs can regulate gene expression by recruiting chromatin modifiers (i.e., SMN-AS1) or by impacting the splicing of the sense coding-strand (i.e., SORL1-AS). Other lncRNAs work independently from their neighboring genes and may act as scaffolds in specific stress related paraspeckles (i.e., NEAT1), rather than regulate mRNA stability by forming RNA-RNA interactions (i.e., BACE1-AS, UCHL1-AS, PINK1-AS).

In spinal muscular atrophy (SMA) mutations in the SMN1 gene, encoding for the survival motor neuron protein (SMN), is the cause of the disease. In addition to SMN1 gene, SMN protein can be also produced by a splicing variant of SMN2, a gene present in variable copies for every individual. When mutations of SMN1 occur, depending on SMN2 copy number, SMA develops showing diverse clinical severities (Gavrilov et al., 1998). d'Ydewalle et al. (2017) identified a SMN antisense transcript (SMN-AS1), whose expression levels increased in neuronal differentiation, inversely correlating with the SMN protein. They found that SMN-AS1 recruits the chromatin modifier PRC2 to the SMN2 promoter repressing its gene expression. SMN-AS1 knock-down dissociates PRC2 from the promoter, thus increasing the overall SMN protein levels in neurons. This indicates that the levels of SMN-AS1 play an important role in the balance of residual SMN protein, thus impacting on the clinical outcome of the SMA disease (d’Ydewalle et al., 2017).

SORL1 antisense RNA (SORL1-AS) is produced from the Sortilin Related Receptor 1 (SORL1), a gene involved in amyloid$\beta$ formation in neuronal cells (Massone et al., 2011). Observations in post-mortem cerebral cortices of Alzheimer disease (AD) compared to healthy individuals showed that SORL1 levels increase and inversely correlate with SORL1-AS (Ciarlo et al., 2013). Ciarlo et al. (2013) found that SORL1-AS expression drives a splicing shift of SORL1 from the synthesis of the canonical long protein variant A to an alternatively spliced protein isoform. This process, resulting in a decreased synthesis of SORL1 variant $\mathrm{A}$, is associated with impaired processing of amyloid precursor protein (APP) leading to increased amyloid $\beta$ formation. The level and the activity of SORL1-AS in the etiology of the disease becomes crucial and may represent an interesting target for future therapeutic strategies (Ciarlo et al., 2013).

NEAT1 is a mammalian lncRNA that is ubiquitously expressed and has a scaffold role in the formation of subnuclear bodies termed paraspeckles. It presents two major isoforms, a 3.7 kb NEAT1_1 and 23 kb NEAT1_2 (Hutchinson et al., 2007). Nishimoto et al. (2013) observed NEAT1_2 to be upregulated during the early stages of amyotrophic lateral sclerosis (ALS) pathogenesis and found it to be present in paraspeckles of ALS patients, providing, for the first 
time, a direct association between paraspeckle formation and neurodegenerative disease (Nishimoto et al., 2013). Paraspeckles are stress-responsive nuclear bodies, which increase in size and number and accompany several physiological as well as pathological stressful conditions (An et al., 2018). Mechanistically, increased paraspeckle formation is observed in ALS and is accompanied by nuclear depletion of TDP-43, a protein frequently dysregulated in ALS (Mackenzie et al., 2010). Indeed, TDP-43 binds NEAT1_2, and when mutated or downregulated affects NEAT1_2 accumulation and paraspeckle assembly (Nishimoto et al., 2013). In Huntington disease (HD), frontotemporal dementia (FTD), and $\mathrm{AD}$ an increase of NEAT1_2 was observed in patient cohorts and experimental studies suggest that NEAT1_2 fine-tunes the function of multiple neurodegeneration-associated pathways, like mitochondrial signaling and miRNA biogenesis (An et al., 2018).

BACE1-AS is an antisense transcript originating from the BACE1 ( $\beta$ secretase 1$)$ gene coding for a protein which is essential for the generation of $\beta$-amyloids. This lncRNA is evolutionarily conserved across vertebrates and was observed to be elevated in subjects with AD and in APP transgenic mice (Faghihi et al., 2008). BACE1-AS has an important role in enhancing the stability of BACE1 mRNA via the formation of a RNA duplex, thus masking miR-485-5p binding sites and leading to an increase of BACE1 protein (Faghihi et al., 2010). The knock-down of this antisense transcript decreases the level of BACE1, reducing amyloid formation and aggregation in the brain. BACE1-AS represents a clear biomarker and potential therapeutic target for the treatment of AD.

Another antisense RNA is UCHL1-AS (ubiquitin carboxyterminal hydrolase L1-antisense) associated with $\mathrm{AD}$, whose activity depends on the presence of a $5^{\prime}$ overlapping sequence with UCHL1 and an embedded inverted SINEUP (SINEB2 sequence to UP-regulate translation). Thanks to the formation of the RNA-RNA duplex with UCHL1 mRNA, UCHL1-AS enhances Cap-independent UCHL1 protein translation under stress condition (Carrieri et al., 2012). UCHL1 expression is associated with a delay of $\mathrm{AD}$, making UCHL1-AS a fundamental regulator of the disease onset and a promising target for therapeutic intervention. Interestingly, both UCHL1 and UCHL1-AS are also found to be downregulated in Parkinson's disease (PD) (Carrieri et al., 2015).

Another antisense transcript, PINK1-AS, is transcribed from the antisense direction of the PINK1 gene (PTEN phosphatase and tensin homolog deleted on chromosome 10-induced putative kinase 1), a gene abundant in mitochondrial-rich tissues and often mutated in PD (Gispert et al., 2009). PINK1-AS controls in cis the expression of a PINK1 splice variant, the svPINK1 transcript, through the formation of a RNA-RNA duplex. The silencing of PINK1-AS results in the reduced expression of svPINK1 in neuronal cells (Scheele et al., 2007). Given that, svPINK1 codes for a homolog of the C-terminus of PINK1, a peptide sequence which regulates PINK1 kinase activity; modulation of PINK1-AS expression may therefore have direct relevance in $\mathrm{PD}$.

Given these examples, it is of no surprise that lncRNAs may play crucial roles in many other molecular processes involved in neurodegeneration. Importantly, except for few reports, most of these molecules are located in proximity or antisense to critical neuronal loci and so the dissection of these specific classes of molecules requires specific attention.

\section{ANTISENSE TRANSCRIPTION OF NUCLEOTIDE REPEAT EXPANSIONS IS INVOLVED IN NEURODEGENERATION}

A conspicuous amount of evidence coming from the transcription of nucleotide expansions emphasizes a role of NATs alongside the coding sense strand in the etiology of neurodegenerative diseases (Salta and De Strooper, 2017; Zucchelli et al., 2019). Here, we describe how nucleotide repeat expansion-associated NATs impact on the disease through complex gain- and loss- of-function mechanisms. One well-exemplified case is described for C9ORF72, a gene that harbors a hexanucleotide repeat expansion representing the most common cause of FTD and ALS. In the mutated loci the sense strand codes for an ORF that produces a repetition of six dipeptide proteins (RAN) forming co-aggregates in the cytoplasm of neurons (DeJesus-Hernandez et al., 2011). This locus is also transcribed in the antisense direction and both the sense/antisense RNA transcripts accumulate to form disease-associated nuclear RNA foci, the number of which correlates with the clinical severity of ALS and FTD (DeJesus-Hernandez et al., 2011; Cooper-Knock et al., 2015a). Interestingly, the knock-down of sense expanded C9ORF72 transcripts through the use of antisense singlestranded oligonucleotides (ASOs) in in vitro derived motor neurons mitigates defects in nucleocytoplasmic transport and glutamate toxicity phenotype, but is not sufficient to fully revert the molecular signatures derived from the hexanucleotide expansion (Donnelly et al., 2013; Lagier-Tourenne et al., 2013; Zhang et al., 2015; Jiang et al., 2016). These findings strongly suggest that the antisense ncRNA and the associated RNA foci contribute to the neurodegenerative phenotype. Notably, antisense C9ORF72 RNA foci hijack RBPs as sense RNA foci but, differently from these, antisense foci are associated with TDP-43 mislocalization in motor neurons from C9ORF72 patients (Cooper-Knock et al., 2014, 2015b). All these findings point to the importance of targeting both sense and antisense expanded C9ORF2 transcripts in order to develop an effective therapeutic approach.

Fragile X mental retardation 1 (FMR1) locus is characterized by the production of multiple non-coding transcripts (FMR5, FMR6, FMR4) in addition to the FMR1 mRNA. Expansion of the CGG triplet in the FMR1 gene ( $>200$ repeats for complete penetrance) is attributed as the main cause of Fragile $\mathrm{X}$ syndrome (FXS), and in a pre-mutation state (55-200 repeats) is responsible for Fragile X-Associated Tremor/Ataxia Syndrome (FXTAS) (Rajan-Babu et al., 2017). Although the pathogenic relevance of all the FMR1 associated transcripts remains to be fully defined, FMR4 is a lncRNA antisense to FMR1 that spans the repeated region and that was observed to significantly affect human cell proliferation and apoptosis in vitro 
(Khalil et al., 2008). Peschansky et al. (2016) confirmed the proliferative effect of FMR4 also in human neural precursor cells (hNPCs) and determined that this lncRNA alters the chromatin state of 100 s of genes in trans, with a significant enrichment for genes involved in neural development and proliferation (Peschansky et al., 2016).

In HD expansion of a CAG-repeat in the huntingtin gene (HTT) results in an elongated polyglutamine stretch and is the main cause of the pathology. From the HTT locus, two ncRNAs are produced: a small CAG containing RNA (sCAG) of around 21 nts with neurotoxic Ago2-dependent activity and an antisense lncRNA (HTT-AS) overlapping with the repeated expansion and observed to be reduced in human HD frontal cortex (Chung et al., 2011; Bañez-Coronel et al., 2012). Additionally, HTT-AS acts as a transcriptional repressor of HTT gene, thus suggesting a protective role of this IncRNA in the penetrance of the disease (Chung et al., 2011).

In spinocerebellular ataxias (SCA) CAG expansions are found in several loci that code for poly-Q SCA proteins. In the SCA8 locus, an antisense transcript (ATXN8-OS/KHL1-AS) that includes the reverse complement of the expansion (CTG) is produced and accumulates in RNA foci in the brain (Moseley et al., 2006); in the SCA7 locus, convergent transcription is also found to produce an antisense SCAANT1 lncRNA. SCAANT1 suppresses SCA7 expression in mice and inversely correlates with SCA7 expression in SCA patients, thus suggesting a loss-of-function mechanism where the IncRNA is involved (Sopher et al., 2011).

Altogether these observations prove that NATs may impact on the penetrance and severity of the clinical symptoms of many neuronal diseases, thus re-centering the attention of the research on new therapeutic strategies and modes of intervention as described in the following paragraphs.

\section{CIRCULAR RNAS IN NEURODEGENERATIVE DISEASES}

Recent investigations have suggested that circRNAs not only function in physiological conditions but that they may also play crucial roles in the occurrence and development of neurological diseases (Table 1).

The first evidence comes from the observation that deficiency or mutations in proteins involved in circRNA biogenesis are linked to the pathogenesis of neurodegenerative diseases: for instance deficiency of QKI may contribute to the development of inherited ataxia while mutations of the FUS gene as well as the deregulation of ADAR2 expression are linked to the pathogenesis of ALS (Chénard and Richard, 2008; Kwiatkowski et al., 2009; Vance et al., 2009; Hideyama et al., 2012; Aizawa et al., 2016).

The implication of circRNAs in neuronal diseases is further supported by studies of expression profiling performed in cellular or animal model systems and by using patients' specimens. Regardless the different modes of action attributed to circRNAs, their activity as miRNA sponges is the only one explored in all the studies reporting implications of these ncRNAs in neuronal disorders. However, this evidence is far from considering the
miRNA sponge activity as a general mode of action of this class of ncRNAs in neurons. Indeed, besides CDR1-AS, most of the circRNAs defined as sponges have only one or a very few binding sites for miRNAs, making the effectiveness of their sponge activity questionable (Li et al., 2019; Ragan et al., 2019). Nevertheless, it has been detected that subsets of circRNAs could act in concert to exert reasonable miRNA sponge function (Ragan et al., 2019).

Huang et al. (2018) have identified more than 300 circRNAs deregulated in the hippocampus of 5- and 10- month-old senescence-accelerated mice P8 (SAMP8), an AD animal model, compared to WT mice. Among them, they characterized mmu_circRNA_017963 circRNA, which might be involved in several cellular processes including apoptosis and synaptic function (Huang et al., 2018). Furthermore, microarray technology combined with RNA-seq analysis allowed to simultaneously characterize circRNA, miRNA and mRNA expression in the hippocampus of an $\mathrm{AD}$ rat model in order to build putative regulatory networks linked to $\mathrm{AD}$ pathogenesis (Wang et al., 2018b).

These analyses identified two possibly AD-linked networks involving the genes Iodothyronine Deiodinase 2 (Dio2) and the high-mobility group box 2 (HMGB2). In particular, the expression of Dio2, that activates myelination, and of HMGB2 which controls the amyloid- $\beta$ plaque clearance, is altered in $\mathrm{AD}$ (Calza et al., 2002; Gao et al., 2011; Humphries et al., 2015; Yamanaka et al., 2015). The networks identified by in-silico analyses have linked the deregulation of these two genes to the aberrant expression of specific circRNAs acting as sponges of mir-122-5p for Dio2 and of let-7-g-3p for HMGB2.

Furthermore, the most expressed and studied circRNA, CDR1-AS, was found reduced in hippocampal CA1 samples from sporadic AD patients compared to controls (Lukiw, 2013). As aforementioned, CDR1-AS has multiple binding sites for miR-7 and its reduction in $\mathrm{AD}$ conditions has been hypothesized to increase the levels miR-7 which in turn targets the ubiquitin protein ligase A (UBE2A). Notably, UBE2A plays an essential function for the proteolytic clearance of amyloid- $\beta$ peptides and its expression is indeed reduced by 2.8 folds in the hippocampal CA1 regions of AD brains (Zhao et al., 2016). Through a similar mechanism CDR1-AS could be also involved in PD since also $\alpha$-synuclein is a target of miR-7 (Junn et al., 2009). Indeed, it has been demonstrated that the repression effect of miR-7 on $\alpha$-synuclein expression in human cell lines can be rescued by the concomitant overexpression of CDR1-AS (Hansen et al., 2013).

CircDLGAP4, originally reported to ameliorate ischemic stroke outcomes, is found to be downregulated in both MPTPinduced PD mouse and MPPp-induced PD cell models (Bai et al., 2018; Feng et al., 2019). Feng et al. (2019) demonstrated that circDLGAP4 participates in PD biological processes regulating miR-134-5p activity. The reduction of CircDLGAP4 expression in PD conditions allows miR-134-5p to repress CREB1 and, as a consequence, the CREB1 target genes including BDNF, Bcl-2 and PGC-1. This would contribute to the development of PD via affecting cell viability, apoptosis, mitochondrial damage and autophagy in human and mouse (Feng et al., 2019).

Deregulation of circRNAs and not of their linear counterparts, has also been reported in in vitro derived motor neurons 
lacking the FUS gene or carrying FUS mutations linked to a severe form of familial ALS (Errichelli et al., 2017; D'Ambra et al., 2019), suggesting a possible role of circRNAs in the pathogenesis of this disorder. In particular, Errichelli et al. (2017) demonstrated that FUS impacts directly on the biogenesis of specific circRNAs through the binding of intronic regions involved in circularization. Whether circRNAs deregulation is caused by loss or gain of function of FUS mutations still remains to be addressed.

\section{NON-CODING RNA DIAGNOSTICS AND THERAPEUTICS}

One of the major challenges for researchers pursuing the understanding and ultimately the treatment of neurological disorders is early diagnosis. By this matter, it is of crucial importance to find suitable molecular markers detectable in patients' specimens obtained through non-invasive methods. In this regards, liquid biopsies are the most applied non-invasive method to measure biomarkers that are soluble in body fluids such as plasma, blood, saliva, and cerebrospinal fluid (CSF). It is believed that circulating molecules potentially reflect the type of disease and can be detected at early stages when other diagnostic tools are not effective (Kelemen et al., 2019).

NcRNAs have been recognized as very important markers in the field of molecular diagnosis since they can be easily detected and quantified in body fluids. LncRNAs and even more circRNAs are high stable while circulating in body fluids, especially when included into extracellular vesicles (Figure 3I). Moreover, they may reflect the origin of the disease because of their tissue specificity. There are many examples of IncRNAs and circRNAs already proposed as possible diagnostic and prognostic biomarkers for various illnesses including cancer, diabetes, Crohn's disease, coronary artery disease, and rheumatoid arthritis (Li et al., 2015b; Ouyang et al., 2017; Zhao et al., 2017; Kelemen et al., 2019). Nevertheless, few reports are available on lncRNAs and circRNAs as biomarkers for neurodegenerative diseases. In particular, Feng et al. (2018) studied the potential of selected lncRNAs as biomarkers in $\mathrm{AD}$ by analyzing plasma from a population of $88 \mathrm{AD}$ patients vs. 72 control individuals. They found that BACE1 lncRNA may be a potential candidate biomarker to predict $\mathrm{AD}$ since it was significantly higher in $\mathrm{AD}$ patients than in healthy controls and showed high specificity (88\%) for $\mathrm{AD}$ (Feng et al., 2018).

In another study the RNA extracted from CSF of a cohort of 27 PD patients and 30 controls was analyzed by RNA-seq: among the differentially expressed transcripts, the lncRNA SCN9 antisense (AC010127.3) and two lncRNAs close to LRRK2 locus (AC079630 and UC001lva.4) have been suggested as potential RNA biomarkers for diagnosis and response to treatment of PD (Hossein-Nezhad et al., 2016).

Moreover, Gagliardi et al. (2018) analyzed lncRNA expression in Peripheral Blood Mononuclear Cells of sporadic ALS and found 293 lncRNAs differentially expressed between normal control and sporadic ALS patients. Among these, NATs of genes which are already linked to neurodegenerative disease (Gagliardi et al., 2018).

As reported by this review, numerous studies have revealed a plethora of IncRNAs and circRNAs differentially expressed and whose activity is altered in disease conditions. This knowledge allows to identify RNA candidates to be used as markers for diagnosis and response to treatments, and even more importantly as potential therapeutic molecules. One interesting example comes from the work on UCHL1AS and its functional role in up-regulating Uchl1 translation (Carrieri et al., 2015). Based on this study, Zucchelli et al. (2015) have designed synthetic SINEUPs to potentially target any mRNA in the cell. One application has been shown very recently in $\mathrm{PD}$, where an increase of GDNF levels is beneficial for the reduction of the neurodegenerative symptoms. Previous therapeutic strategies to increase GDNF levels have produced side effects due to high ectopic doses of this factor (Kordower and Bjorklund, 2013). Using a PD mouse model and adeno associated viral (AAV) delivery of miniSINEUPs, a twofold increase of GDNF was observed in dopaminergic neurons, thus ameliorating motor deficits of the mice (Espinoza et al., 2020). MiniSINUPs are an encouraging approach for the increase of endogenous GDNF levels in patients and may represent a unique RNA-based therapeutic platform to address many other diseases.

A promising strategy to target ncRNAs takes advantage of the use of ASOs designed to bind perfectly to target transcripts, inducing either their enzymatic degradation or inhibition of the binding of RBPs required for RNA maturation/activity. It is likely that ASOs targeting NATs represents a powerful tool for novel therapeutic strategies, considering that NATs are pervasively associated with coding genes loci and have an impact on the regulation of neuronal genes. For instance, ASOs designed against BACE1-AS and SMN1-AS have been tested in murine and human model systems and have provided proofs of principle that these NATs are clinically relevant novel therapeutic targets for $\mathrm{AD}$ and SMA respectively. Notably, the downregulation of BACE1-AS in an AD mouse model lowers the amyloid- $\beta$ levels and ameliorates adult neurogenesis while reduced levels of SMN1-AS increases the transcription of SMN2 gene in patient-derived cells, in SMA neurons, and in a mouse model of severe SMA (Modarresi et al., 2011; d'Ydewalle et al., 2017). As demonstrated in these two cases, the increase of knowledge concerning the biology of NATs in normal and disease states still represents the most important milestone to achieve in order to develop and design novel therapeutic approaches.

Another example of ncRNA used as potential therapeutic target is the repeat-containing C9orf72 transcript. A new approach that has been employed to knock-down these transcripts is the use of artificial miRNAs (miC). Notably, Martier et al. (2019) proved, in vivo, the delivery and efficacy of AAV5$\mathrm{miC}$ in cortex and hippocampal neurons of $\mathrm{Tg}(\mathrm{C} 9 \mathrm{orf72} 33)$ ALS mouse model thus providing a proof of concept for the use of this strategy in the treatment of ALS and FTD.

Differently to lncRNAs, the field of circRNA research is still in its infancy and even though the use of these RNAs 
in the diagnosis and treatment of neurological disorders can be foreseen, we are still far from employing circRNAs in clinical practice.

Indeed, aside from the study by Cui et al. (2016), observing modulation of hsa_circRNA_103636 expression in peripheral blood mononuclear cells of patients with major depressive disorder treated with antidepressants for 8 weeks, the potential use of circRNAs as biomarkers in neurological diseases has not been well-explored yet. Additionally, the study by Cui et al. (2016) suggests that circulating circRNAs can be also used to assess responses to drug treatments.

The potential use of circRNAs in therapy comes from evidence suggesting that the accumulation of ciRNAs in the cytoplasm, caused by the inhibition of debranching enzyme 1 (Dbr1) activity, suppresses the toxicity of TDP-43 aggregates in human neuronal cell line and primary rat neurons (Armakola et al., 2012). ciRNAs might act as decoys for TDP-43 thus avoiding its interaction with other cellular RNAs in the cytoplasm. Since TDP-43 is deposited in protein aggregates in neurons and glia in $>96 \%$ of ALS cases, the modulation of ciRNAs biogenesis by targeting Dbr1 might represent a therapeutic strategy for ALS and other related TDP-43 proteinopathies.

Lastly, one important point of discussion arises for the delivery of therapeutic molecules to central nervous system (CNS) since the blood-brain barrier (BBB) and blood spinal cord barrier (BSCB) represents a bottleneck in the development of new therapies to treat CNS diseases. Indeed, in the last decade a great deal of effort has been dedicated to the achievement of an efficient and effective drug delivery to CNS focusing on the types of administration as well as on the design and modification of the potential therapeutic molecules (Krizbai et al., 2016; Kumar et al., 2017; Alexander et al., 2019; Fowler et al., 2020). A promising approach to circumvent the $\mathrm{BBB}$ and the $\mathrm{BSCB}$ is the delivery of therapeutic molecules directly to CNS through intrathecal injection (IT). Indeed, ASOs or AAV based molecules that have been IT administrated through intracerebroventricular (ICV) injection in rodent models and non-human primates, showed a widespread distribution in brain and spinal cord indicating the feasibility of this approach in targeting tissues mostly affected in neurodegenerative diseases (DeVos and Miller, 2013; Rigo et al., 2014; Biferi et al., 2017; Casaca-Carreira et al., 2017; Schoch and Miller, 2017; Martier et al., 2019). More importantly, pre-clinical and clinical trials involving IT/ICV delivery of ASOs against disease-associated transcripts (SMN, SOD1, and C9ORF72) have demonstrated the effectiveness and tolerability of this approach (Miller et al., 2013; Finkel et al., 2016; Cappella et al., 2019; Neil and Bisaccia, 2019).

\section{PERSPECTIVES}

The knowledge derived from the studies on ncRNAs has increased exponentially in the last decade. Advances from international consortia, such as the FANTOM and the ENCODE projects for the functional identification of the whole transcriptome repertoire, have created a clear picture that extended regions of the genome are actively transcribed and contain previously undiscovered functional elements. Ambitious projects for the characterization of novel functions of noncoding transcripts and in particular of lncRNAs and circRNAs have deepened our understanding on the regulatory processes that underlie higher eukaryotes molecular complexity. This is particularly intriguing for the study of the nervous system, where tissue and cellular complexity seem to be evolutionary associated with an increase of non-coding genes number, expression and activity (Qureshi and Mehler, 2012). In this review we have described how IncRNAs and circRNAs are involved in controlling multiple neuronal functions in physiological as well as in pathological conditions. However, in this latter case most of the experimental studies focused on the differential expression of ncRNAs in disease respect to healthy conditions, while only partial information on ncRNA functions is available so far. Surprisingly, ncRNAs act through very diverse modes of action and, except few cases, no common feature is known to predict the function, making the study of each lncRNA or circRNA an incredibly challenging process.

The development of murine and cellular model systems, such as patient derived Induced Plutipotent Stem Cells efficiently differentiated through specific protocols, represent powerful model systems for the study of ncRNA functions in neurodegenerative diseases (Dawson et al., 2018; Wu et al., 2019). Indeed, these systems offer the opportunity to compare healthy with disease conditions providing mechanistic insights into molecular principles of neurodegenerative biology. The study of ncRNAs in these contexts might provide a unique resource for high-throughput functional screenings of non-coding genes involved in neurodegeneration.

Moreover, the use of model systems as well as patient specimens could represent a helpful resource for the identification of candidates having therapeutic potential, particularly in the preclinical stages when the neuronal loss is still minimal leading to a more effective intervention. As described in this review efforts to attain this goal have already started.

\section{AUTHOR CONTRIBUTIONS}

MM and BS wrote and revised the manuscript. SB prepared figures and revised the manuscript.

\section{FUNDING}

MM was supported by ARISLA pilot grant 2017 (circRNALS); BS and SB are supported by Istituto Italiano di Tecnologia (IIT).

\section{ACKNOWLEDGMENTS}

We are grateful to Alessandro Fatica and Irene Bozzoni for valuable discussion and suggestions We thank Valentina Silenzi for proofreading the manuscript. 


\section{REFERENCES}

Aizawa, H., Hideyama, T., Yamashita, T., Kimura, T., Suzuki, N., et al. (2016). Deficient RNA-editing enzyme ADAR2 in an amyotrophic lateral sclerosis patient with a FUS(P525L) mutation. J. Clin. Neurosci. 32, 128-129. doi: 10. 1016/j.jocn.2015.12.039

Aktaş, T., Avşar Ilık, Ý, Maticzka, D., Bhardwaj, V., Pessoa Rodrigues, C., Mittler, G., et al. (2017). DHX9 suppresses RNA processing defects originating from the Alu invasion of the human genome. Nature 544, 115-119. doi: 10.1038/ nature 21715

Alexander, A., Agrawal, M., Uddin, A., Siddique, S., Shehata, A. M., Shaker, M. A., et al. (2019). Recent expansions of novel strategies towards the drug targeting into the brain. Int. J. Nanomed. 14, 5895-5909. doi: 10.2147/IJN.S210876

An, H., Williams, N. G., and Shelkovnikova, T. A. (2018). NEAT1 and paraspeckles in neurodegenerative diseases: a missing lnc found? Noncod. RNA Res. 3, 243-252. doi: 10.1016/j.ncrna.2018.11.003

Anderson, D. M., Anderson, K. M., Chang, C. L., Makarewich, C. A., Nelson, B. R., McAnally, J. R., et al. (2015). A micropeptide encoded by a putative long noncoding RNA regulates muscle performance. Cell 4, 595-606. doi: 10.1016/j. cell.2015.01.009

Aprea, J., Prenninger, S., Dori, M., Ghosh, T., Monasor, L. S., Wessendorf, E., et al. (2013). Transcriptome sequencing during mouse brain development identifies long non-coding RNAs functionally involved in neurogenic commitment. EMBO J. 32, 3145-3160. doi: 10.1038/emboj.2013.245

Armakola, M., Higgins, M. J., Figley, M. D., Barmada, S. J., Scarborough, E. A., Diaz, Z., et al. (2012). Inhibition of RNA lariat debranching enzyme suppresses TDP-43 toxicity in ALS disease models. Nat. Genet. 44, 1302-1309. doi: 10.1038/ ng. 2434

Ashwal-Fluss, R., Meyer, M., Pamudurti, N. R., Ivanov, A., Bartok, O., Hanan, M., et al. (2014). circRNA biogenesis competes with Pre-mRNA splicing. Mol. Cell 56, 55-66. doi: 10.1016/j.molcel.2014.08.019

Bach, D. H., Lee, S. K., and Sood, A. K. (2019). Circular RNAs in cancer. Mol. Ther. Nucleic Acids 16, 118-129. doi: 10.1016/j.omtn.2019.02.005

Bai, Y., Zhang, Y., Han, B., Yang, L., Chen, X., Huang, R., et al. (2018). Circular RNA DLGAP4 ameliorates ischemic stroke out- comes by targeting miR-143 to regulate endothelial-mesenchymal transition associated with blood-brain barrier integrity. J. Neurosci. 38, 32-50. doi: 10.1523/JNEUROSCI.1348-17.2017

Ballarino, M., Cipriano, A., Tita, R., Santini, T., Desideri, F., Morlando, M., et al. (2018). Deficiency in the nuclear long noncoding RNA Charme causes myogenic defects and heart remodeling in mice. EMBO J. 37:e99697. doi: 10. 15252/embj.201899697

Bañez-Coronel, M., Porta, S., Kagerbauer, B., Mateu-Huertas, E., Pantano, L., Ferrer, I., et al. (2012). A pathogenic mechanism in Huntington's disease involves small CAG-repeated RNAs with neurotoxic activity. PLoS Genet. 8:e1002481. doi: 10.1371/journal.pgen.1002481

Barrett, S. P., Wang, P. L., and Salzman, J. (2015). Circular RNA biogenesis can proceed through an exon-containing lariat precursor. eLife 4:e07540. doi: 10. 7554/eLife.07540

Bartolomei, M. S., Zemel, S., and Tilghman, S. M. (1991). Parental imprinting of the mouse H19 gene. Nature 351, 153-155. doi: 10.1038/351153a0

Berghoff, E. G., Clark, M. F., Chen, S., Cajigas, I., Leib, D. E., and Kohtz, J. D. (2013). Evf2 (Dlx6as) IncRNA regulates ultraconserved enhancer methylation and the differential transcriptional control of adjacent genes. Development 140, 4407-4416. doi: 10.1242/dev.099390

Bernard, D., Prasanth, K. V., Tripathi, V., Colasse, S., Nakamura, T., Xuan, Z., et al. (2010). A long nuclear-retained non-coding RNA regulates synaptogenesis by modulating gene expression. EMBO J. 29, 3082-3093. doi: 10.1038/emboj. 2010.199

Biferi, M. G., Cohen-Tannoudji, M., Cappelletto, A., Giroux, B., Roda, M., Astord, S., et al. (2017). A new AAV10-U7-mediated gene therapy prolongs survival and restores function in an als mouse model. Mol. Ther. 25, 2038-2052. doi: 10.1016/j.ymthe.2017.05.017

Biscarini, S., Capauto, D., Peruzzi, G., Lu, L., Colantoni, A., Santini, T., et al. (2018). Characterization of the IncRNA transcriptome in mESC-derived motor neurons: implications for FUS-ALS. Stem Cell Res. 27, 172-179. doi: 10.1016/j. scr.2018.01.037

Bond, A. M., Vangompel, M. J., Sametsky, E. A., Clark, M. F., Savage, J. C., Disterhoft, J. F., et al. (2009). Balanced gene regulation by an embryonic brain ncRNA is critical for adulthippocampal GABA circuitry. Nat. Neurosci. 2, 1020-1027. doi: 10.1038/nn.2371

Brown, C. J., Ballabio, A., Rupert, J. L., Lafreniere, R. G., Grompe, M., Tonlorenzi, R., et al. (1991). A gene from the region of the human X inactivation centre is expressed exclusively from the inactive X chromosome. Nature 349, 38-44. doi: 10.1038/349038a0

Cabili, M. N., Dunagin, M. C., McClanahan, P. D., Biaesch, A., Padovan-Merhar, O., Regev, A., et al. (2015). Localization and abundance analysis of human lncRNAs at single-cell and single-molecule resolution. Genome Biol. 16:20. doi: 10.1186/s13059-015-0586-4

Cabili, M. N., Trapnell, C., Goff, L., Koziol, M., Tazon-Vega, B., Regev, A., et al. (2011). Integrative annotation of human large intergenic noncoding RNAs reveals global properties and specific subclasses. Genes Dev. 25, 1915-1927. doi: $10.1101 /$ gad.17446611

Calza, L., Fernandez, M., Giuliani, A., Aloe, L., and Giardino, L. (2002). Thyroid hormone activates oligodendrocyte precur- sors and increases a myelinforming protein and NGF content in the spinal cord during experimental allergic encephalomyelitis. Proc. Natl. Acad. Sci. U.S.A. 99, 3258-3263. doi: 10.1073/pnas.052704499

Cappella, M., Ciotti, C., Cohen-Tannoudji, M., and Biferi, M. G. (2019). Gene therapy for ALS-A perspective. Int. J. Mol. Sci. 20, E4388. doi: 10.3390/ ijms 20184388

Carninci, P., Kasukawa, T., Katayama, S., Gough, J., Frith, M. C., Maeda, N., et al. (2005). The transcriptional landscape of the mammalian genome. Science 309, 1559-1563. doi: 10.1126/science.1112014

Carrieri, C., Cimatti, L., Biagioli, M., Beugnet, A., Zucchelli, S., Fedele, S., et al. (2012). Long non-coding antisense RNA controls Uchll translation through anembedded SINEB2 repeat. Nature 491, 454-457. doi: 10.1038/nature 11508

Carrieri, C., Forrest, A. R., Santoro, C., Persichetti, F., Carninci, P., Zucchelli, S., et al. (2015). Expression analysis of the long non-coding RNA antisense to Uchl1 (AS Uchl1) during dopaminergic cells' differentiation in vitro and in neurochemical models of Parkinson's disease. Front. Cell Neurosci. 9:114. doi: $10.3389 /$ fncel. 2015.00114

Casaca-Carreira, J., Temel, Y., Larrakoetxea, I., and Jahanshahi, A. (2017). Distribution and penetration of intracerebroventricularly administered 20OMePS oligonucleotide in the mouse brain. Nucleic Acid Ther. 27, 4-10. doi: $10.1089 /$ nat.2016.0642

Cesana, M., Cacchiarelli, D., Legnini, I., Santini, T., Sthandier, O., Chinappi, et al. (2011). A long noncoding RNA controls muscle differentiation by functioning as a competing endogenous RNA. Cell 147, 358-369. doi: 10.1016/j.cell.2011. 09.028

Chen, B. J., Huang, S., and Janitz, M. (2018a). Changes in circular RNA expression patterns during human foetal brain development. Genomics 111, 753-758. doi: 10.1016/j.ygeno.2018.04.015

Chen, N., Zhao, G., Yan, X., Lv, Z., Yin, H., Zhang, S., et al. (2018b). A novel FLI1 exonic circular RNA promotes metastasis in breast cancer by coordinately regulating TET1 and DNMT1. Genome Biol. 19:218. doi: 10.1186/s13059-0181594-y

Chénard, C. A., and Richard, S. (2008). New implications for the QUAKING RNA binding protein in human disease. J. Neurosci. Res. 86, 233-242. doi: 10.1002/ jnr.21485

Chu, C., Qu, K., Zhong, F. L., Artandi, S. E., and Chang, H. Y. (2011). Genomic maps of long noncoding RNA occupancy reveal principles of RNA-chromatin interactions. Mol. Cell 44, 667-678. doi: 10.1016/j.molcel.2011.08.027

Chung, D. W., Rudnicki, D. D., Yu, L., and Margolis, R. L. (2011). A natural antisense transcript at the Huntington's disease repeat locus regulates HTT expression. Hum. Mol. Genet. 20, 3467-3477. doi: 10.1093/hmg/ ddr263

Ciarlo, E., Massone, S., Penna, I., Nizzari, M., Gigoni, A., Dieci, G., et al. (2013). An intronic ncRNA-dependent regulation of SORL1 expression affecting A $\beta$ formation is upregulated in post-mortem Alzheimer's disease brain samples. Dis. Model Mech. 6, 424-433. doi: 10.1242/dmm.009761

Conn, S. J., Pillman, K. A., Toubia, J., Conn, V. M., Salmanidis, M., Phillips, C. A., et al. (2015). The RNA binding protein quaking regulates formation of circRNAs. Cell 160, 1125-1134. doi: 10.1016/j.cell.2015.02.014

Cooper, D. R., Carter, G., Li, P., Patel, R., Watson, J. E., and Patel, N. A. (2014). Long non-coding RNA NEAT1 associates with SRp40 to temporally regulate 
PPAR $\gamma 2$ splicing during adipogenesis in 3T3-L1 cells. Genes 5, 1050-1063. doi: 10.3390/genes5041050

Cooper-Knock, J., Kirby, J., Highley, R., and Shaw, P. J. (2015a). The spectrum of C9orf72-mediated neurodegeneration and amyotrophic lateral sclerosis. Neurotherapeutics 12, 326-339. doi: 10.1007/s13311-015-0342-1

Cooper-Knock, J., Higginbottom, A., Stopford, M. J., Highley, J. R., Ince, P. G., Wharton, S. B., et al. (2015b). Antisense RNA foci in the motor neurons of C9ORF72-ALS patients are associated with TDP-43 proteinopathy. Acta Neuropathol. 130, 63-75. doi: 10.1007/s00401-015-1429-9

Cooper-Knock, J., Walsh, M. J., Higginbottom, A., Robin Highley, J., Dickman, M. J., Edbauer, D., et al. (2014). Sequestration of multiple RNA recognition motif-containing proteins by C9orf72 repeat expansions. Brain 137, 2040-2051. doi: 10.1093/brain/awu120

Costa-Mattioli, M., Sossin, W. S., Klann, E., and Sonenberg, N. (2009). Translational control of long-lasting synaptic plasticity and memory. Neuron 61, 10-26. doi: 10.1016/j.neuron.2008.10.055

Cui, X., Niu, W., Kong, L., He, M., Jiang, K., Chen, S., et al. (2016). hsa_circRNA_103636: potential novel diagnostic and therapeutic biomarker in Major depressive disorder. Biomark. Med. 10, 943-952. doi: 10.2217/bmm2016-0130

D'Ambra, E., Capauto, D., and Morlando, M. (2019). Exploring the regulatory role of circular rnas in neurodegenerative disorders. Int. J. Mol. Sci. 20, E5477. doi: 10.3390/ijms20215477

Dawson, T. M., Golde, T. E., and Lagier-Tourenne, C. (2018). Animal models of neurodegenerative diseases. Nat. Neurosci. 21, 1370-1379. doi: 10.1038/s41593018-0236-8

DeJesus-Hernandez, M., Mackenzie, I. R., Boeve, B. F., Boxer, A. L., Baker, M., Rutherford, N. J., et al. (2011). Expanded GGGGCC hexanucleotide repeat in noncoding region of C9ORF72 causes chromosome 9p-linked FTD and ALS. Neuron 72, 245-256. doi: 10.1016/j.neuron.2011.09.011

Derrien, T., Johnson, R., Bussotti, G., Tanzer, A., Djebali, S., Tilgner, H., et al. (2012). The GENCODE $\mathrm{v} 7$ catalog of human long noncoding RNAs: analysis of their gene structure, evolution, and expression. Genome Res. 22, 1775-1789. doi: $10.1101 /$ gr.132159.111

Derrien, T., Johnson, R., Bussotti, G., Tanzer, A., Djebali, S., Tilgner, H., et al. (2014). The four dimensions of noncoding RNA conservation. Trends Genet. 30, 121-123. doi: 10.1016/j.tig.2014.01.004

DeVos, S. L., and Miller, T. M. (2013). Direct intraventricular delivery of drugs to the rodent central nervous system. J. Vis. Exp. 12:e50326. doi: 10.3791/ 50326

Dimartino, D., Colantoni, A., Ballarino, M., Martone, J., Mariani, D., Danner, J., et al. (2018). The long non-coding RNA lnc-31 interacts with Rock1 mRNA and mediates Its YB-1-dependent translation. Cell Rep. 23, 733-740. doi: 10.1016/j. celrep.2018.03.101

Donnelly, C. J., Zhang, P. W., Pham, J. T., Haeusler, A. R., Mistry, N. A., Vidensky, S., et al. (2013). RNA toxicity from the ALS/FTD C9ORF72 expansion is mitigated by antisense intervention. Neuron $80,415-428$. doi: $10.1016 / j$.neuron. 2013.10.015

Du, W. W., Fang, L., Yang, W., Wu, N., Awan, F. M., Yang, Z., et al. (2017). Induction of tumor apoptosis through a circular RNA enhancing Foxo3 activity. Cell Death Differ. 24, 357-370. doi: 10.1038/cdd.2016.133

d'Ydewalle, C., Ramos, D. M., Pyles, N. J., Ng, S. Y., Gorz, M., Pilato, C. M., et al. (2017). The antisense transcript SMN-AS1 regulates SMN expression and is a novel therapeutic target for spinal muscular atrophy. Neuron $93,66-79$. doi: $10.1016 /$ j.neuron.2016.11.033

Engreitz, J. M., Ollikainen, N., and Guttman, M. (2016). Long non-coding RNAs: spatial amplifiers that control nuclear structure and gene expression. Nat. Rev. Mol. Cell Biol. 17, 756-770. doi: 10.1038/nrm.126

Engreitz, J. M., Pandya-Jones, A., McDonel, P., Shishkin, A., Sirokman, K., Surka, C., et al. (2013). The Xist lncRNA exploits three-dimensional genome architecture to spread across the X chromosome. Science 341:1237973. doi: $10.1126 /$ science. 1237973

Errichelli, L., Dini Modigliani, S., Laneve, P., Colantoni, A., Legnini, I., Capauto, D., et al. (2017). FUS affects circular RNA expression in murine embryonic stem cell-derived motor neurons. Nat. Commun. 8:14741. doi: 10.1038/ ncomms 14741

Espinoza, S., Scarpato, M., Damiani, D., Managò, F., Mereu, M., Contestabile, A., et al. (2020). SINEUP non-coding RNA targeting GDNF rescues motor deficits and neurodegeneration in a mouse model of parkinson's disease. Mol. Ther. 28, 642-652. doi: 10.1016/j.ymthe.2019.08.005

Faghihi, M. A., Modarresi, F., Khalil, A. M., Wood, D. E., Sahagan, B. G., Morgan, T. E., et al. (2008). Expression of a noncoding RNA is elevated in Alzheimer's disease and drives rapid feed-forward regulation of beta-secretase. Nat. Med. 14, 723-730. doi: 10.1038/nm1784

Faghihi, M. A., Zhang, M., Huang, J., Modarresi, F., Van der Brug, M. P., Nalls, M. A., et al. (2010). Evidence for natural antisense transcript-mediated inhibition of microRNA function. Genome Biol. 11:R56. doi: 10.1186/gb-201011-5-r56

Fatica, A., and Bozzoni, I. (2014). Long non-coding RNAs: new players in cell differentiation and development. Nat. Rev. Genet. 15, 7-21. doi: 10.1038/ nrg3606

Fei, T., Chen, Y., Xiao, T., Li, W., Cato, L., Zhang, P., et al. (2017). Genome-wide CRISPR screen identifies HNRNPL as a prostate cancer dependency regulating RNA splicing. Proc. Natl. Acad. Sci. U.S.A. 114, E5207-E5215. doi: 10.1073/ pnas. 1617467114

Feng, L., Liao, Y. T., He, J. C., Xie, C. L., Chen, S. Y., Fan, H. H., et al. (2018). Plasma long non-coding RNA BACE1 as a novel biomarker for diagnosis of Alzheimer disease. BMC Neurol. 18:4. doi: 10.1186/s12883-017-1008-x

Feng, Z., Zhang, L., Wang, S., and Hong, Q. (2019). Circular RNA circDLGAP4 exerts neuroprotective effects via modulating miR-134-5p/CREB pathway in Parkinson's disease. Biochem. Biophys. Res. Commun. 522, 388-394. doi: 10. 1016/j.bbrc.2019.11.102

Finkel, R. S., Chiriboga, C. A., Vajsar, J., Day, J. W., Montes, J., De Vivo, D. C., et al. (2016). Treatment of infantile-onset spinal muscular atrophy with nusinersen: a phase 2, open- label, dose-escalation study. Lancet 388, 3017-3026. doi: 10. 1016/S0140-6736(16)31408-8

Fowler, M. J., Cotter, J. D., Knight, B. E., Sevick-Muraca, E. M., Sandberg, D. I., and Sirianni, R. W. (2020). Intrathecal drug delivery in the era of nanomedicine. Adv. Drug Deliv. Rev. doi: 10.1016/j.addr.2020.02.006 [Epub ahead of print].

Gagliardi, S., Zucca, S., Pandini, C., Diamanti, L., Bordoni, M., Sproviero, D., et al. (2018). Long non-coding and coding RNAs characterization in peripheral blood mononuclear cells and spinal cord from amyotrophic lateral sclerosis patients. Sci. Rep. 8:2378. doi: 10.1038/s41598-018-20679-5

Gao, H. M., Zhou, H., Zhang, F., Wilson, B. C., Kam, W., and Hong, J. S. (2011). HMGB1 acts on microglia MAC1 to mediate chronic neuroinflammation that drives progressive neurodegeneration. J. Neurosci. 31, 1081-1092. doi: 10.1523/ JNEUROSCI.3732-10.2011

Gavrilov, D. K., Shi, X., Das, K., Gilliam, T. C., and Wang, C. H. (1998). Differential SMN2 expression associated with SMA severity. Nat. Genet. 20, 230-231. doi: $10.1038 / 3030$

Gispert, S., Ricciardi, F., Kurz, A., Azizov, M., Hoepken, H. H., Becker, D., et al. (2009). Parkinson phenotype in aged PINK1-deficient mice is accompanied by progressive mitochondrial dysfunction in absence of neurodegeneration. PLoS ONE 4:e5777. doi: 10.1371/journal.pone.0005777

Glazar, P., Papavasileiou, P., and Rajewsky, N. (2014). circBase: a database for circular RNAs. RNA 20, 1666-1670. doi: 10.1261/rna.043687.113

Gong, C., Li, Z., Ramanujan, K., Clay, I., Zhang, Y., Lemire-Brachat, S., et al. (2015). A long non-coding RNA, LncMyoD, regulates skeletal muscle differentiation by blocking IMP2-mediated mRNA translation. Dev. Cell 34, 181-191. doi: 10.1016/j.devcel.2015.05.009

Gong, C., and Maquat, L. E. (2011). IncRNAs transactivate STAU1-mediated mRNA decay by duplexing with 3', UTRs via Alu elements. Nature 470, 284-288. doi: 10.1038/nature09701

Gruner, H., Cortés-López, M., Cooper, D. A., Bauer, M., and Miura, P. (2016). CircRNA accumulation in the aging mouse brain. Sci. Rep. 6:38907. doi: 10 . 1038/srep38907

Guttman, M., Amit, I., Garber, M., French, C., Lin, M. F., Feldser, D., et al. (2009). Chromatin signature reveals over a thousand highly conserved large non-coding RNAs in mammals. Nature 458, 223-227. doi: 10.1038/nature07672

Guttman, M., Donaghey, J., Carey, B. W., Garber, M., Grenier, J. K., Munson, G., et al. (2011). lincRNAs act in the circuitry controlling pluripotency and differentiation. Nature 477, 295-300. doi: 10.1038/nature10398

Hacisuleyman, E., Goff, L. A., Trapnell, C., Williams, A., Henao-Mejia, J., Sun, L., et al. (2014). Topological organization of multichromosomal regions by the long intergenic noncoding RNA Firre. Nat. Struct. Mol. Biol. 21, 198-206. doi: $10.1038 / \mathrm{nsmb} .2764$ 
Hangauer, M. J., Vaughn, I. W., and McManus, M. T. (2013). Pervasive transcription of the human genome produces thousands of previously unidentified long intergenic noncoding RNAs. PLoS Genet. 9:e1003569. doi: 10.1371/journal.pgen.1003569

Hansen, T. B. (2018). Improved circRNA identification by combining prediction algorithms. Front. Cell Dev. Biol. 6:20. doi: 10.3389/fcell.2018.00020

Hansen, T. B., Jensen, T. I., Clausen, B. H., Bramsen, J. B., Finsen, B., Damgaard, C. K., et al. (2013). Natural RNA circles function as efficient microRNA sponges. Nature 495, 384-388. doi: 10.1038/nature11993

Hideyama, T., Yamashita, T., Aizawa, H., Tsuji, S., Kakita, A., Takahashi, H., et al. (2012). Profound downregulation of the RNA editing enzyme ADAR2 in ALS spinal motor neurons. Neurobiol. Dis. 45, 1121-1128. doi: 10.1016/j.nbd.2011. 12.033

Hon, C. C., Ramilowski, J. A., Harshbarger, J., Bertin, N., Rackham, O. J., Gough, J., et al. (2017). An atlas of human long non-coding RNAs with accurate $5^{\prime}$ ends. Nature 543, 199-204. doi: 10.1038/nature21374

Hossein-Nezhad, A., Fatemi, R. P., Ahmad, R., Peskind, E. R., Zabetian, C. P., Hu, S. C., et al. (2016). Transcriptomic profiling of extracellular RNAs present in cerebrospinal fluid identifies differentially expressed transcripts in Parkinson's disease. J. Parkinsons Dis. 6, 109-117. doi: 10.3233/JPD-150737

Huang, J. L., Qin, M. C., Zhou, Y., Xu, Z. H., Yang, S. M., Zhang, F., et al. (2018). Comprehensive analysis of differentially expressed profiles of Alzheimer's disease associated circular RNAs in an Alzheimer's disease mouse model. Aging 10, 253-265. doi: 10.18632/aging.101387

Hube, F., and Francastel, C. (2018). Coding and non-coding RNAs, the frontier has never been so blurred. Front. Genet. 9:140. doi: 10.3389/fgene.2018.00140

Humphries, C. E., Kohli, M. A., Nathanson, L., Whitehead, P., Beecham, G., Martin, E., et al. (2015). Integrated whole transcriptome and DNA methylation analysis identifies gene networks specific to late-onset Alzheimer's disease. J. Alzheimers Dis. 44, 977-987. doi: 10.3233/JAD-141989

Hunter, C. S., and Rhodes, S. J. (2005). LIM-homeodomain genes in mammalian development and human disease. Mol. Biol. Rep. 32, 67-77. doi: 10.1007/ s11033-004-7657-z

Hutchinson, J. N., Ensminger, A. W., Clemson, C. M., Lynch, C. R., Lawrence, J. B., and Chess, A. (2007). A screen for nuclear transcripts identifies two linked noncoding RNAs associated with SC35 splicing domains. BMC Genomics 8:39. doi: 10.1186/1471-2164-8-39

Ingolia, N. T. (2014). Ribosome profiling: new views of translation, from single codons to genome scale. Nat. Rev. Genet. 15, 205-213. doi: 10.1038/nrg3645

Ivanov, A., Memczak, S., Wyler, E., Torti, F., Porath, H. T., Orejuela, M. R., et al. (2015). Analysis of intron sequences reveals hallmarks of circular RNA biogenesis in animals. Cell Rep. 10, 170-177. doi: 10.1016/j.celrep.2014.12.019

Jeck, W. R., and Sharpless, N. E. (2014). Detecting and characterizing circular RNAs. Nat. Biotechnol. 32, 453-461. doi: 10.1038/nbt.2890

Jeck, W. R., Sorrentino, J. A., Wang, K., Slevin, M. K., Burd, C. E., Liu, J., et al. (2013). Circular RNAs are abundant, conserved, and associated with ALU repeats. RNA 19, 141-157. doi: 10.1261/rna.035667.112

Jenny, O., Hachet, P., Zavorszky, A., Cyrklaff, M. D., Weston, D. S., Johnston, M., et al. (2006). translation-independent role of oskar RNA in early Drosophila oogenesis. Development 133, 2827-2833. doi: 10.1242/dev.02456

Ji, P., Diederichs, S., Wang, W., Boing, S., Metzger, R., Schneider, P. M., et al. (2003). MALAT-1, a novel noncoding RNA, and thymosin beta4 predict metastasis and survival in early-stage non-small cell lung cancer. Oncogene 22, 8031-8041. doi: 10.1038/sj.onc.1206928

Jiang, J., Zhu, Q., Gendron, T. F., Saberi, S., McAlonis-Downes, M., Seelman, A., et al. (2016). Gain of toxicity from ALS/FTD-linked repeat expansions in C9ORF72 is alleviated by antisense oligonucleotides targeting GGGGCCcontaining RNAs. Neuron 90, 535-550. doi: 10.1016/j.neuron.2016.04.006

Junn, E., Lee, K. W., Jeong, B. S., Chan, T. W., Im, J. Y., and Mouradian, M. M. (2009). Repression of alpha-synuclein expression and toxicity by microRNA7. Proc. Natl. Acad. Sci. U.S.A. 106, 13052-13057. doi: 10.1073/pnas.090627 7106

Kelemen, E., Danis, J., Göblös, A., Bata-Csörgõ, Z., and Széll, M. (2019). Exosomal long non-coding RNAs as biomarkers in human diseases. EJIFCC 30, 224-236.

Khalil, A. M., Faghihi, M. A., Modarresi, F., Brothers, S. P., and Wahlestedt, C. (2008). A novel RNA transcript with antiapoptotic function is silenced in fragile $\mathrm{X}$ syndrome. PLoS ONE 3:e1486. doi: 10.1371/journal.pone.0001486
Kim, T. K., Hemberg, M., Gray, J. M., Costa, A. M., Bear, D. M., Wu, J., et al. (2010). Wide-spread transcription at neuronal activity-regulated enhancers. Nature 465, 182-1871. doi: 10.1038/nature09033

Kleaveland, B., Shi, C. Y., Stefano, J., and Bartel, D. P. (2018). A network of noncoding regulatory RNAs acts in the mammalian brain. Cell 174, 350-362. doi: 10.1016/j.cell.2018.05.022

Kordower, J. H., and Bjorklund, A. (2013). Trophic factor gene therapy for Parkinson's disease. Mov. Disord. 28, 96-109. doi: 10.1002/mds.25344

Kos, A., Dijkema, R., Arnberg, A. C., van der Meide, P. H., and Schellekens, H. (1986). The hepatitis delta (Delta) virus possesses a circular RNA. Nature 323, 558-560. doi: 10.1038/323558a0

Kramer, M. C., Liang, D., Tatomer, D. C., Gold, B., March, Z. M., Cherry, S., et al. (2015). Combinatorial control of Drosophila circular RNA expression by intronic repeats, hnRNPs, and SR proteins. Genes Dev. 29, 2168-2182. doi: 10.1101/gad.270421.115

Kretz, M., Siprashvili, Z., Chu, C., Webster, D. E., Zehnder, A., Qu, K., et al. (2013). Control of somatic tissue differentiation by the long non-coding RNA TINCR. Nature 493, 231-235. doi: 10.1038/nature11661

Kristensen, L. S., Andersen, M. S., Stagsted, L. V. W., Ebbesen, K. K., Hansen, T. B., and Kjems, J. (2019). The biogenesis, biology and characterization of circular RNAs. Nat. Rev. Genet. 20, 675-691. doi: 10.1038/s41576-019-0158-7

Krizbai, I. A., Nyúl-Tóth, Á, Bauer, H. C., Farkas, A. E., Traweger, A., Haskó, J., et al. (2016). Pharmaceutical targeting of the brain. Curr. Pharm. Des. 22, 5442-5462. doi: 10.2174/1381612822666160726144203

Kumar, H., Mishra, G., Sharma, A. K., Gothwal, A., Kesharwani, P., et al. (2017). Intranasal drug delivery: a non-invasive approach for the better delivery of neurotherapeutics. Pharm. Nanotechnol. 5, 203-214. doi: 10.2174/ 2211738505666170515113936

Kwiatkowski, T. J. Jr., Bosco, D. A., Leclerc, A. L., Tamrazian, E., Vanderburg, C. R., Russ, et al. (2009). Mutations in the FUS/TLS gene on chromosome 16 cause familial amyotrophic lateral sclerosis. Science 323, 1205-1208. doi: $10.1126 /$ science. 1166066

Lagier-Tourenne, C., Baughn, M., Rigo, F., Sun, S., Liu, P., Li, H. R., et al. (2013). Targeted degradation of sense and antisense C9orf72 RNA foci as therapy for ALS and frontotemporal degeneration. Proc. Natl. Acad. Sci. U.S.A. 110, E4530-E4539. doi: 10.1073/pnas.1318835110

Lai, F., Orom, U. A., Cesaroni, M., Beringer, M., Taatjes, D. J., Blobel, G. A., et al. (2013). Activating RNAs associate with Mediator to enhance chromatin architecture and transcription. Nature 494, 497-501. doi: 10.1038/nature11884

Lander, E. S., Linton, L. M., Birren, B., Nusbaum, C., Zody, M. C., Baldwin, J., et al. (2001). Initial sequencing and analysis of the human genome. Nature 409, 860-921. doi: $10.1038 / 35057062$

Legnini, I., Di Timoteo, G., Rossi, F., Morlando, M., Briganti, F., Sthandier, O., et al. (2017). Circ-ZNF609 is a circular RNA that can be translated and functions in myogenesis. Mol. Cell 66:22. doi: 10.1016/j.molcel.2017.02.017

Leucci, E., Vendramin, R., Spinazzi, M., Laurette, P., Fiers, M., Wouters, J., et al. (2016). Melanoma addiction to the long non-coding RNA SAMMSON. Nature 531, 518-522. doi: 10.1038/nature17161

Li, H. M., Ma, X. L., and Li, H. G. (2019). Intriguing circles: conflicts and controversies in circular RNA research. Wiley Interdiscip. Rev. RNA 29:e1538. doi: 10.1002/wrna.1538

Li, L. J., Leng, R. X., Fan, Y. G., Pan, H. F., and Ye, D. Q. (2017). Translation of noncoding RNAs: focus on IncRNAs, pri-miRNAs, and circRNAs. Exp. Cell Res. 361, 1-8. doi: 10.1016/j.yexcr.2017.10.010

Li, Z., Huang, C., Bao, C., Chen, L., Lin, M., Wang, X., et al. (2015a). Exon-intron circular RNAs regulate transcription in the nucleus. Nat. Struct. Mol. Biol. 22, 256-264. doi: 10.1038/nsmb.2959

Li, Y., Zheng, Q., Bao, C., Li, S., Guo, W., Zhao, J., et al. (2015b). Circular RNA is enriched and stable in exosomes: a promising biomarker for cancer diagnosis. Cell Res. 25, 981-984. doi: 10.1038/cr.2015.82

Liang, D., and Wilusz, J. E. (2014). Short intronic repeat sequences facilitate circular RNA production. Genes Dev. 28, 2233-2247. doi: 10.1101/gad.2519 26.114

Liang, W. C., Wong, C. W., Liang, P. P., Shi, M., Cao, Y., Rao, S. T., et al. (2019). Translation of the circular RNA $\operatorname{circ} \beta$-catenin promotes liver cancer cell growth through activation of the Wnt pathway. Genome Biol. 20:84. doi: 10.1186/s13059-019-1685-4 
Lipovich, L., Dachet, F., Cai, J., Bagla, S., Balan, K., Jia, H., et al. (2012). Activitydependent human brain coding/noncoding gene regulatory networks. Genetics 192, 1133-1148. doi: 10.1534/genetics.112.145128

Liu, C. X., Li, X., Nan, F., Jiang, S., Gao, X., Guo, S. K., et al. (2019). Structure and degradation of circular RNAs regulate PKR activation in innate immunity. Cell 177, 865-880. doi: 10.1016/j.cell.2019.03.046

Lu, D., and Xu, A. D. (2016). Mini review: circular RNAs as potential clinical biomarkers for disorders in the central nervous system. Front. Genet. 7:237. doi: 10.3389/fgene.2016.00053

Lukiw, W. J. (2013). Circular RNA (circRNA) in Alzheimer's disease (AD). Front. Genet. 4:307. doi: 10.3389/fgene.2013.00307

Machado, C. B., Kanning, K. C., Kreis, P., Stevenson, D., Crossley, M., Nowak, M., et al. (2014). Reconstruction of phrenic neuron identity in embryonic stem cell-derived motor neurons. Development 141, 784-794. doi: 10.1242/dev. 097188

Mackenzie, I. R., Rademakers, R., and Neumann, M. (2010). TDP-43 and FUS in amyotrophic lateral sclerosis and frontotemporal dementia. Lancet Neurol. 9, 995-1007. doi: 10.1016/S1474-4422(10)70195-2

Mao, Y. S., Sunwoo, H., Zhang, B., and Spector, D. L. (2011). Direct visualization of the co-transcriptional assembly of a nuclear body by noncoding RNAs. Nat. Cell Biol. 13, 95-101. doi: 10.1038/ncb2140

Martier, R., Liefhebber, J. M., García-Osta, A., Miniarikova, J., Cuadrado-Tejedor, M., Espelosin, M., et al. (2019). Targeting RNA-mediated toxicity in C9orf72 ALS and/or FTD by RNAi-based gene therapy. Mol. Ther. Nucleic Acids 16, 26-37. doi: 10.1016/j.omtn.2019.02.001

Massone, S., Vassallo, I., Fiorino, G., Castelnuovo, M., Barbieri, F., Borghi, R., et al. (2011). A, a novel non-coding RNA, regulates GABA B alternative splicing and signaling in response to inflammatory stimuli and in Alzheimer disease. Neurobiol. Dis. 41, 308-317. doi: 10.1016/j.nbd.2010.09.019

Mele, M., and Rinn, J. L. (2016). "Cat's cradling" the 3D genome by the act of LncRNA transcription. Mol. Cell 62, 657-664. doi: 10.1016/j.molcel.2016. 05.011

Memczak, S., Jens, M., Elefsinioti, A., Torti, F., Krueger, J., Rybak, A., et al. (2013). Circular RNAs are a large class of animal RNAs with regulatory potency. Nature 495, 333-338. doi: 10.1038/nature11928

Mercer, T. R., Dinger, M. E., Sunkin, S. M., Mehler, M. F., and Mattick, J. S. (2008). Specific expression of long noncoding RNAs in the mouse brain. Proc. Natl. Acad. Sci. U.S.A. 105, 716-721. doi: 10.1073/pnas.0706729105

Mercer, T. R., Qureshi, I. A., Gokhan, S., Dinger, M. E., Li, G., Mattick, J. S., et al. (2010). Long noncoding RNAs in neuronal-glial fate specification and oligodendrocyte lineage maturation. BMC Neurosci. 11:14. doi: 10.1186/14712202-11-14

Meyer, D., Bonhoeffer, T., and Scheuss, V. (2014). Balance and stability of synaptic structures during synaptic plasticity. Neuron 82, 430-443. doi: 10.1016/ j.neuron.2014.02.031

Miller, T. M., Pestronk, A., David, W., Rothstein, J., Simpson, E., Appel, S. H., et al. (2013). An antisense oligonucleotide against SOD1 delivered intrathecally for patients with SOD1 familial amyotrophic lateral sclerosis: a phase 1, randomised, first-in-man study. Lancet Neurol. 12, 435-442. doi: 10.1016/ S1474-4422(13)70061-9

Modarresi, F., Faghihi, M. A., Lopez-Toledano, M. A., Fatemi, R. P., Magistri, M., Brothers, S. P., et al. (2012). Inhibition of natural antisense transcripts in vivo results in gene-specific transcriptional upregulation. Nat. Biotechnol. 30, 453-459. doi: 10.1038/nbt.2158

Modarresi, F., Faghihi, M. A., Patel, N. S., Sahagan, B. G., Wahlestedt, C., and Lopez-Toledano, M. A. (2011). Knockdown of BACE1-AS nonprotein-coding transcript modulates $B$-amyloid- related hippocampal neurogenesis. Int. J. Alzheimers. Dis. 2011:929042. doi: 10.4061/2011/929042

Morlando, M., and Fatica, A. (2018). Alteration of epigenetic regulation by long noncoding RNAs in cancer. Int. J. Mol. Sci. 9, E570. doi: 10.3390/ijms19020570

Mortazavi, A., Williams, B. A., McCue, K., Schaeffer, L., and Wold, B. (2008). Mapping and quantifying mammalian transcriptomes by RNA-seq. Nat. Methods 5, 621-628. doi: 10.1038/nmeth.1226

Moseley, M. L., Zu, T., Ikeda, Y., Gao, W., Mosemiller, A. K., Daughters, R. S., et al. (2006). Bidirectional expression of CUG and CAG expansion transcripts and intranuclear polyglutamine inclusions in spinocerebellar ataxia type 8. Nat. Genet. 38, 758-769. doi: 10.1038/ng1827
Muslimov, I. A., Banker, G., Brosius, J., and Tiedge, H. (1998). Activity-depen- dent regulation of dendritic BC1 RNA in hippocampal neurons in culture. J. Cell Biol. 141, 1601-1611. doi: 10.1083/jcb.141.7.1601

Muslimov, I. A., Santi, E., Homel, P., Perini, S., Higgins, D., and Tiedge, H. (1997). RNA transport in dendrites: a cis-acting targeting element is contained within neuronal BC1 RNA. J. Neurosci. 17, 4722-4733. doi: 10.1523/jneurosci.17-1204722.1997

Neil, E. E., and Bisaccia, E. K. (2019). Nusinersen: a novel antisense oligonucleotide for the treatment of spinal muscular atrophy. J. Pediatr. Pharmacol. Ther. 24, 194-203. doi: 10.5863/1551-6776-24.3.194

Nelson, B. R., Makarewich, C. A., Anderson, D. M., Winders, B. R., Troupes, C. D., $\mathrm{Wu}, \mathrm{F}$., et al. (2016). A peptide encoded by a transcript annotated as long noncoding RNA enhances SERCA activity in muscle. Science 351, 271-275. doi: $10.1126 /$ science.aad 4076

Ng, S. Y., Bogu, G. K., Soh, B. S., and Stanton, L. W. (2013). The long noncoding RNA RMST interacts with SOX2 to regulate neurogenesis. Mol. Cell 51, 349359. doi: 10.1016/j.molcel.2013.07.017

Ng, S. Y., Johnson, R., and Stanton, L. W. (2012). Human long non-coding RNAs promote pluripotency and neuronal differentiation by association with chromatin modifiers and transcription factors. EMBO J. 31, 522-533. doi: 10 . 1038/emboj.2011.459

Nishimoto, Y., Nakagawa, S., Hirose, T., Okano, H. J., Takao, M., Shibata, S., et al. (2013). The long non-coding RNA nuclear-enriched abundant transcript $1 \_2$ induces paraspeckle formation in the motor neuron during the early phase of amyotrophic lateral sclerosis. Mol. Brain 6:31. doi: 10.1186/1756-66066-31

Osborne, C. S., Chakalova, L., Brown, K. E., Carter, D., Horton, A., Debrand, E., et al. (2004). Active genes dynamically colocalize to shared sites of ongoing transcription. Nat. Genet. 36, 1065-1071. doi: 10.1038/ng1423

Osenberg, S., Paz Yaacov, N., Safran, M., Moshkovitz, S., Shtrichman, R., Sherf, O., et al. (2010). Alu sequences in undifferentiated human embryonic stem cells display high levels of A-to-I RNA editing. PLoS ONE 5:e11173. doi: 10.1371/ journal.pone.0011173

Ouyang, Q., Wu, J., Jiang, Z., Zhao, J., Wang, R., Lou, A., et al. (2017). Microarray expression profile of circular RNAs in peripheral blood mononuclear cells from rheumatoid arthritis patients. Cell. Physiol. Biochem. 42, 651-659. doi: 10.1159/ 000477883

Pamudurti, N. R., Bartok, O., Jens, M., Ashwal-Fluss, R., Stottmeister, C., Ruhe, L., et al. (2017). Translation of CircRNAs. Mol. Cell 66:9. doi: 10.1016/j.molcel. 2017.02.021

Panda, A. C., De, S., Grammatikakis, I., Munk, R., Yang, X., Piao, Y., et al. (2017). High-purity circular RNA isolation method (RPAD) reveals vast collection of intronic circRNAs. Nucleic Acids Res. 45, e116. doi: 10.1093/nar/gkx297

Peschansky, V. J., Pastori, C., Zeier, Z., Wentzel, K., Velmeshev, D., Magistri, M., et al. (2016). The long non-coding RNA FMR4 promotes proliferation of human neural precursor cells and epigenetic regulation of gene expression in trans. Mol. Cell. Neurosci. 74, 49-57. doi: 10.1016/j.mcn.2016.03.008

Piwecka, M., Glažar, P., Hernandez-Miranda, L. R., Memczak, S., Wolf, S. A., et al. (2017). Loss of a mammalian circular RNA locus causes miRNA deregulation and affects brain function. Science 357:eaam8526. doi: 10.1126/science.aam8526

Quinn, J. J., and Chang, H. Y. (2016). Unique features of long non-coding RNA biogenesis and function. Nat. Rev. Genet. 17, 47-62. doi: 10.1038/nrg.2015.10

Qureshi, I. A., Mattick, J. S., and Mehler, M. F. (2010). Long non-coding RNAs in nervous system function and disease. Brain Res. 1338c, 20-35. doi: 10.1016/j. brainres.2010.03.110

Qureshi, I. A., and Mehler, M. F. (2012). Emerging roles of non-coding RNAs in brain evolution, development, plasticity, and disease. Nat. Rev. Neurosci. 3, 528-541. doi: 10.1038/nrn3234

Rackham, O., Shearwood, A.-M. J., Mercer, T. R., Davies, S. M. K., Mattick, J. S., and Filipovska, A. (2011). Long noncoding RNAs are generated from the mitochondrial genome and regulated by nuclear-encoded proteins. RNA 17, 2085-2093. doi: 10.1261/rna.029405.111

Ragan, C., Goodall, G. J., Shirokikh, N. E., and Preiss, T. (2019). Insights into the biogenesis and potential functions of exonic circular RNA. Sci. Rep. 9:2048. doi: 10.1038/s41598-018-37037-0

Rajan-Babu, I. S., Lian, M., Cheah, F. S. H., Chen, M., Tan, A. S. C., Prasath, E. B., et al. (2017). FMR1 CGG repeat expansion mutation detection and linked 
haplotype analysis for reliable and accurate preimplantation genetic diagnosis of fragile X syndrome. Expert Rev. Mol. Med. 19:e10. doi: 10.1017/erm. 2017.10

Ramos, A. D., Andersen, R. E., Liu, S. J., Nowakowski, T. J., Hong, S. J., Gertz, C., et al. (2015). The long noncoding RNA Pnky regulates neuronal differentiation of embryonic and postnatal neural stem cells. Cell Stem Cell 16, 439-447. doi: 10.1016/j.stem.2015.02.007

Rigo, F., Chun, S. J., Norris, D. A., Hung, G., Lee, S., Matson, J., et al. (2014). Pharmacology of a central nervous system delivered 20-O-methox-yethylmodified survival of motor neuron splicing oligonucleotide in mice and nonhuman primates. J. Pharmacol. Exp. Ther. 350, 46-55. doi: 10.1124/jpet.113. 212407

Rinn, J. L., and Chang, H. Y. (2012). Genome regulation by long noncoding RNAs. Annu. Rev. Biochem. 81, 145-166. doi: 10.1146/annurev-biochem-051410092902

Rinn, J. L., Kertesz, M., Wang, J. K., Squazzo, S. L., Xu, X., Brugmann, S. A., et al. (2007). Functional demarcation of active and silent chromatin domains in human HOX loci by noncoding RNAs. Cell 129, 1311-1323. doi: 10.1016/j. cell.2007.05.022

Romero-Barrios, N., Legascue, M. F., Benhamed, M., Ariel, F., and Crespi, M. (2018). Splicing regulation by long noncoding RNAs. Nucleic Acids Res. 46, 2169-2184. doi: 10.1093/nar/gky095

Rossi, F., Legnini, I., Megiorni, F., Colantoni, A., Santini, T., Morlando, M., et al. (2019). Circ-ZNF609 regulates G1-S progression in rhabdomyosarcoma. Oncogene 38, 3843-3854. doi: 10.1038/s41388-019-0699-4

Rybak-Wolf, A., Stottmeister, C., Glažar, P., Jens, M., Pino, N., Giusti, S., et al. (2015). Circular RNAs in the mammalian brain are highly abundant, conserved, and dynamically expressed. Mol. Cell 58, 870-885. doi: 10.1016/j.molcel.2015. 03.027

Salta, E., and De Strooper, B. (2017). Noncoding RNAs in neurodegeneration. Nat. Rev. Neurosci. 18, 627-640. doi: 10.1038/nrn.2017.90

Salzman, J. (2014). Circular RNA is expressed across the eukaryotic tree of life. PLoS ONE 9:e90859. doi: 10.1371/journal.pone.0090859

Salzman, J., Gawad, C., Wang, P. L., Lacayo, N., and Brown, P. O. (2012). Circular RNAs are the predominant transcript isoform from hundreds of human genes in diverse cell types. PLoS ONE 7:E30733. doi: 10.1371/journal.pone.0030733

Sanger, H. L., Klotz, G., Riesner, D., Gross, H. J., and Kleinschmidt, A. K. (1976). Viroids are single-stranded covalently closed circular RNA molecules existing as highly base-paired rod- like structures. Proc. Natl. Acad. Sci. U.S.A. 73, 3852-38562. doi: 10.1073/pnas.73.11.3852

Scheele, C., Petrovic, N., Faghihi, M. A., Lassmann, T., Fredriksson, K., Rooyackers, O., et al. (2007). The human PINK1 locus is regulated in vivo by a non-coding natural antisense RNA during modulation of mitochondrial function. BMC Genomics 8:74. doi: 10.1186/1471-2164-8-74

Schoch, K. M., and Miller, T. M. (2017). Antisense oligonucleotides: translation from mouse models to human neurodegenerative diseases. Neuron 94, 10561070. doi: 10.1016/j.neuron.2017.04.010

Shao, Y., and Chen, Y. (2016). Roles of circular RNAs in neurologic disease. Front. Mol. Neurosci. 9:25. doi: 10.3389/fnmol.2016.00025

Sigova, A. A., Mullen, A. C., Molinie, B., Gupta, S., Orlando, D. A., et al. (2013). Divergent transcription of long noncoding RNA/mRNA gene pairs inembryonic stem cells. Proc. Natl. Acad. Sci. U.S.A. 110, 2876-2881. doi: 10. 1073/pnas. 1221904110

Smith, M. A., Gesell, T., Stadler, P. F., and Mattick, J. S. (2013). Widespread purifying selection on RNA structure in mammals. Nucleic Acids Res. 41, 8220-8236. doi: 10.1093/nar/gkt596

Sopher, B. L., Ladd, P. D., Pineda, V. V., Libby, R. T., Sunkin, S. M., Hurley, J. B., et al. (2011). CTCF regulates ataxin-7 expression through promotion of a convergently transcribed, antisense noncoding RNA. Neuron 70, 1071-1084. doi: 10.1016/j.neuron.2011.05.027

Sun, S., Del Rosario, B. C., Szanto, A., Ogawa, Y., Jeon, Y., and Lee, J. T. (2013). Jpx RNA activates Xist by evicting CTCF. Cell 153, 1537-1551. doi: 10.1016/j.cell. 2013.05.028

Szabo, L., and Salzman, J. (2016). Detecting circular RNAs: bioinformatic and experimental challenges. Nat. Rev. Genet. 17, 679-692. doi: 10.1038/nrg. 2016.114

Tavares, L., Dimitrova, E., Oxley, D., Webster, J., Poot, R., Demmers, J., et al. (2012). RYBP-PRC1 complexes mediate H2A ubiquitylation at polycomb target sites independently of PRC2 and H3K27me3. Cell 148, 664-678. doi: 10.1016/j.cell. 2011.12.029

Tripathi, V., Ellis, J. D., Shen, Z., Song, D. Y., Pan, Q., Watt, A. T., et al. (2010). The nuclear-retained noncoding RNA MALAT1 regulates alternative splicing by modulating SR splicing factor phosphorylation. Mol. Cell 39, 925-938. doi: 10.1016/j.molcel.2010.08.011

Tsuchida, T., Ensini, M., Morton, S. B., Baldassare, M., Edlund, T., Jessell, T. M., et al. (1994). Topographic organization of embryonic motor neurons defined by expression of LIM homeobox genes. Cell 79, 957-970. doi: 10.1016/00928674(94)90027-2

Ulitsky, I., Shkumatava, A., Jan, C. H., Sive, H., and Bartel, D. P. (2011). Conserved function of lincRNAs in vertebrate embryonic development despite rapid sequence evolution. Cell 147, 1537-1550. doi: 10.1016/j.cell.2011.11.055

van Rossum, D., Verheijen, B. M., and Pasterkamp, R. J. (2016). Circular RNAs: novel regulators of neuronal development. Front. Mol. Neurosci. 9:74. doi: 10.3389/fnmol.2016.00074

Vance, C., Rogelj, B., Hortobágyi, T., De Vos, K. J., Nishimura, A. L., Sreedharan, J., et al. (2009). Mutations in FUS, an RNA processing protein, cause familial amyotrophic lateral sclerosis type 6. Science 323, 1208-1211. doi: 10.1126/ science.1165942

Vance, K. W., Sansom, S. N., Lee, S., Chalei, V., Kong, L., Cooper, S. E., et al. (2014). The long non-coding RNA Paupar regulates the expression of both local and distal genes. EMBO J. 33, 296-311. doi: 10.1002/embj.201386225

Venø, M. T., Hansen, T. B., Venø, S. T., Clausen, B. H., Grebing, M., Finsen, B., et al. (2015). Spatio-temporal regulation of circular RNA expression during porcine embryonic brain development. Genome Biol. 16, 1-17.

Wang, D. Q., Fu, P., Yao, C., Zhu, L. S., Hou, T. Y., Chen, J. G., et al. (2018a). Long non-coding RNAs, novel culprits, or bodyguards in neurodegenerative diseases. Mol. Ther. Nucleic Acids 10, 269-276. doi: 10.1016/j.omtn.2017.12.011

Wang, H., Iacoangeli, A., Popp, S., Muslimov, I. A., Imataka, H., Sonenberg, N., et al. (2002). Dendritic BC1 RNA: functional role in regulation of translation initiation. J. Neurosci. 22, 10232-10241. doi: 10.1523/jneurosci.22-23-10232. 2002

Wang, K. C., and Chang, H. Y. (2011). Molecular mechanisms of long noncoding RNAs. Mol. Cell 43, 904-914. doi: 10.1016/j.molcel.2011.08.018

Wang, K. C., Yang, Y. W., Liu, B., Sanyal, A., Corces-Zimmerman, R., Chen, Y., et al. (2011). A long noncoding RNA maintains active chromatin to coordinate homeotic gene expression. Nature 472, 120-124. doi: 10.1038/nature09819

Wang, P. L., Bao, Y., Yee, M. C., Barrett, S. P., Hogan, G. J., Olsen, M. N., et al. (2013). Endogenous miRNA sponge lincRNA-RoR regulates Oct4, Nanog, and Sox2 in human embryonic stem cell self-renewal. Dev. Cell 25, 69-80. doi: 10.1016/j.devcel.2013.03.002

Wang, P. L., Bao, Y., Yee, M. C., Barrett, S. P., Hogan, G. J., Olsen, M. N., et al. (2014). Circular RNA is expressed across the eukaryotic tree of life. PLoS ONE 9:e90859. doi: 10.1371/journal.pone.0090859

Wang, Z., Xu, P., Chen, B., Zhang, Z., Zhang, C., Zhan, Q., et al. (2018b). Identifying circRNA-associated-ceRNA networks in the hippocampus of Abeta1-42- induced Alzheimer's disease-like rats using microarray analysis. Aging 10, 775-788. doi: 10.18632/aging.101427

Wanowska, E., Kubiak, M. R., Rosikiewicz, W., Makałowska, I., and Szcześniak, M. W. (2018). Natural antisense transcripts in diseases: from modes of action to targeted therapies. Wiley Interdiscip. Rev. RNA 9:e1461. doi: 10.1002/wrna.1461

Wei, C. W., Luo, T., Zou, S. S., and Wu, A. S. (2018). The role of long noncoding RNAs in central nervous system and neurodegenerative diseases. Front. Behav. Neurosci. 12:175. doi: 10.3389/fnbeh.2018.00175

West, A. E., and Greenberg, M. E. (2011). Neuronal activity-regulated gene transcription in synapse development and cognitive function. Cold Spring Harb Perspect Biol. 3:a005744. doi: 10.1101/cshperspect.a005744

Westholm, J. O., Miura, P., Olson, S., Shenker, S., Joseph, B., Sanfilippo, P., et al. (2014). Genome-wide analysis of drosophila circular RNAs reveals their structural and sequence properties and age-dependent neural accumulation. Cell Rep. 9, 1966-1980. doi: 10.1016/j.celrep.2014.10.062

Wu, Y. Y., Chiu, F. L., Yeh, C. S., and Kuo, H. C. (2019). Opportunities and challenges for the use of induced pluripotent stem cells in modelling neurodegenerative disease. Open Biol. 9:180177. doi: 10.1098/rsob.180177

Xu, K., Chen, D., Wang, Z., Ma, J., Zhou, J., Chen, N., et al. (2018). Annotation and functional clustering of circRNA expression in rhesus macaque brain during aging. Cell Discov. 4:48. doi: 10.1038/s41421-018-0050-1 
Yamanaka, Y., Faghihi, M. A., Magistri, M., Alvarez-Garcia, O., Lotz, M., and Wahlestedt, C. (2015). Antisense RNA controls LRP1 sense transcript expression through interaction with a chromatin- associated protein, HMGB2. Cell Rep. 11, 967-976. doi: 10.1016/j.celrep.2015.04.011

Yang, Y., Fan, X., Mao, M., Song, X., Wu, P., Zhang, Y., et al. (2017). Extensive translation of circular RNAs driven by N(6)-methyladenosine. Cell Res. 27, 626-641. doi: 10.1038/cr.2017.31

Yang, Y., Gao, X., Zhang, M., Yan, S., Sun, C., Xiao, F., et al. (2018). Novel role of FBXW7 circular RNA in repressing glioma tumorigenesis. J. Natl. Cancer Inst. 110, 304. doi: 10.1093/jnci/djx166

Yoon, J. H., Abdelmohsen, K., Srikantan, S., Yang, X., Martindale, J. L., De, S., et al. (2012). LincRNA-p21 suppresses target mRNA translation. Mol. Cell 47, 648-655. doi: 10.1016/j.molcel.2012.06.027

You, X., Vlatkovic, I., Babic, A., Will, T., Epstein, I., Tushev, G., et al. (2015). Neural circular RNAs are derived from synaptic genes and regulated by development and plasticity. Nat. Neurosci. 18, 603-610. doi: 10.1038/nn.3975

Yu, W., Gius, D., Onyango, P., Muldoon-Jacobs, K., Karp, J., Feinberg, A. P., et al. (2008). Epigenetic silencing of tumor suppressor gene 15 by its antisense RNA. Nature 451, 202-206. doi: 10.1038/nature06468

Zalfa, F., Giorgi, M., Primerano, B., Moro, A., Di Penta, A., Reis, S., et al. (2003). The fragile $\mathrm{X}$ syndrome protein FMRP associates with $\mathrm{BC} 1 \mathrm{RNA}$ and regulates the translation of specific mRNAs at synapses. Cell 112, 317-327. doi: 10.1016/ s0092-8674(03)00079-5

Zeng, Y., Du, W. W., Wu, Y., Yang, Z., Awan, F. M., Li, X., et al. (2017). A circular RNA binds to and activates AKT phosphorylation and nuclear localization reducing apoptosis and enhancing cardiac repair. Theranostics 7, 3842-3855. doi: 10.7150/thno.19764

Zhang, K., Donnelly, C. J., Haeusler, A. R., Grima, J. C., Machamer, J. B., Steinwald, P., et al. (2015). The C9orf72 repeat expansion disrupts nucleocytoplasmic transport. Nature 525, 56-61. doi: 10.1038/nature14973

Zhang, M., Huang, N., Yang, X., Luo, J., Yan, S., Xiao, F., et al. (2018a). A novel protein encoded by the circular form of the SHPRH gene suppresses glioma tumorigenesis. Oncogene 37:1805. doi: 10.1038/s41388-017-0019-9

Zhang, X., Rice, K., Wang, Y., Chen, W., Zhong, Y., Nakayama, Y., et al. (2010). Maternally expressed gene 3 (MEG3) noncoding ribonucleic acid: isoform structure, expression, and functions. Endocrinology 151, 939-947. doi: 10.1210/ en.2009-0657

Zhang, X. O., Wang, H. B., Zhang, Y., Lu, X., Chen, L. L., and Yang, L. (2014). Complementary sequence-mediated exon circularization. Cell 159, 134-147. doi: 10.1016/j.cell.2014.09.001

Zhang, Y., Du, L., Bai, Y., Han, B., He, C., Gong, L., et al. (2018b). CircDYM ameliorates depressive-like behavior by targeting miR-9 to regulate microglial activation via HSP90 ubiquitination. Mol. Psychiatry doi: 10.1038/s41380-0180285-0 [Epub ahead of print].

Zhang, Y., Liu, X. S., Liu, Q. R., and Wei, L. (2006). Genome-wide in silico identification and analysis of cis natural antisense transcripts
(cis-NATS) in ten species. Nucleic Acids Res. 34, 3465-3475. doi: 10.1093/nar/ gkl473

Zhang, Y., Zhang, X. O., Chen, T., Xiang, J. F., Yin, Q. F., Xing, Y. H., et al. (2013). Circular intronic long noncoding RNAs. Mol. Cell 51, 792-806. doi: 10.1016/j.molcel.2013.08.017

Zhao, J., Ohsumi, T. K., Kung, J. T., Ogawa, Y., Grau, D. J., Sarma, K., et al. (2010). Genome-wide identification of polycomb-associated RNAs by RIP-seq. Mol. Cell 40, 939-953. doi: 10.1016/j.molcel.2010.12.011

Zhao, Y., Alexandrov, P. N., Jaber, V., and Lukiw, W. J. (2016). Deficiency in the ubiquitin conjugating enzyme UBE2A in Alzheimer's disease (AD) is linked to deficits in a natural circular miRNA-7 sponge (circRNA, ciRS-7). Genes 7:E116. doi: $10.3390 /$ genes7120116

Zhao, Z., Li, X., Jian, D., Hao, P., Rao, L., and Li, M. (2017). Hsa_circ_0054633 in peripheral blood can be used as a diagnostic biomarker of pre-diabetes and type 2 diabetes mellitus. Acta Diabetol. 54, 237-245. doi: 10.1007/s00592-0160943-0

Zheng, Q., Bao, C., Guo, W., Li, S., Chen, J., Chen, B., et al. (2016). Circular RNA profiling reveals an abundant circHIPK3 that regulates cell growth by sponging multiple miRNAs. Nat. Commun. 7:11215. doi: 10.1038/ncomms11215

Zhong, J., Chuang, S. C., Bianchi, R., Zhao, W., Lee, H., Fenton, A. A., et al. (2009). BC1 regulation of metabotropic glutamate receptor-mediated neuronal excitability. J. Neurosci. 29, 9977-9986. doi: 10.1523/JNEUROSCI.389308.2009

Zink, D., Amaral, M. D., Englmann, A., Lang, S., Clarke, L. A., Rudolph, C., et al. (2004). Transcription-dependent spatial arrangements of CFTR and adjacent genes in human cell nuclei. J. Cell Biol. 166, 815-825. doi: 10.1083/ jcb. 200404107

Zucchelli, S., Fasolo, F., Russo, R., Cimatti, L., Patrucco, L., Takahashi, H., et al. (2015). SINEUPs are modular antisense long non-coding RNAs that increase synthesis of target proteins in cells. Front. Cell Neurosci. 9:174. doi: 10.3389/ fncel.2015.00174

Zucchelli, S., Fedele, S., Vatta, P., Calligaris, R., Heutink, P., Rizzu, P., et al. (2019). FANTOM Consortium, Gustincich S. antisense transcription in loci associated to hereditary neurodegenerative diseases. Mol. Neurobiol. 56, 5392-5415. doi: 10.1007/s12035-018-1465- doi: 10.1007/s12035-018-1465-2

Conflict of Interest: The authors declare that the research was conducted in the absence of any commercial or financial relationships that could be construed as a potential conflict of interest.

Copyright (c) 2020 Salvatori, Biscarini and Morlando. This is an open-access article distributed under the terms of the Creative Commons Attribution License (CC BY). The use, distribution or reproduction in other forums is permitted, provided the original author(s) and the copyright owner(s) are credited and that the original publication in this journal is cited, in accordance with accepted academic practice. No use, distribution or reproduction is permitted which does not comply with these terms. 